\title{
Polyvinylidene fluoride nanocomposite super hydrophilic membrane integrated with Polyaniline-Graphene oxide nano fillers for treatment of textile effluents
}

Dol:

10.1016/j.jhazmat.2020.123587

\author{
Document Version \\ Accepted author manuscript
}

Link to publication record in Manchester Research Explorer

Citation for published version (APA):

Nawaz, H., Umar, M., Ullah, A., Razzaq, H., Zia, K. M., \& Liu, X. (2021). Polyvinylidene fluoride nanocomposite super hydrophilic membrane integrated with Polyaniline-Graphene oxide nano fillers for treatment of textile effluents. Journal of Hazardous Materials, 403, [123587]. https://doi.org/10.1016/j.jhazmat.2020.123587

\section{Published in:}

Journal of Hazardous Materials

\section{Citing this paper}

Please note that where the full-text provided on Manchester Research Explorer is the Author Accepted Manuscript or Proof version this may differ from the final Published version. If citing, it is advised that you check and use the publisher's definitive version.

\section{General rights}

Copyright and moral rights for the publications made accessible in the Research Explorer are retained by the authors and/or other copyright owners and it is a condition of accessing publications that users recognise and abide by the legal requirements associated with these rights.

\section{Takedown policy}

If you believe that this document breaches copyright please refer to the University of Manchester's Takedown Procedures [http://man.ac.uk/04Y6Bo] or contact uml.scholarlycommunications@manchester.ac.uk providing relevant details, so we can investigate your claim.

\section{OPEN ACCESS}


1 Polyvinylidene fluoride nanocomposite super hydrophilic membrane 2 integrated with Polyaniline-Graphene oxide nano fillers for treatment of textile 3 effluents

4 Hifza Nawaz ${ }^{\text {a }}$,Muhammad Umar ${ }^{\mathrm{b}}$, Azeem Ullah ${ }^{\mathrm{c}}$, Humaira Razzaq $^{\mathrm{a}}$, Khalid Mahmood Zia ${ }^{\mathrm{d}}$, 5 Xuqing $\operatorname{Liu}^{\mathrm{b}, *}$

6

7 a Department of Chemistry, Quaid-i-Azam University, Islamabad 45320, Pakistan;

8 hafsanawaz1122@gmail.com; humaira.razzaq@uow.edu.pk

$9 \quad{ }^{b}$ Department of Materials, University of Manchester, Oxford Road, Manchester, M13 9PL, UK;

10 muhammad.umar@manchester.ac.uk

$11{ }^{\mathrm{c}}$ Nano Fusion Technology Research Lab, Institute for Fiber Engineering (IFES), Interdisciplinary 12 Cluster for Cutting Edge Research (ICCER), Shinshu University, Matsumoto, Nagano 390-8621, 13 Japan; 08tex101@gmail.com

$14{ }^{\mathrm{d}}$ Department of Applied Chemistry, Government College University, Faisalabad 38030, Pakistan; 15 drkmzia@gcuf.edu.pk

16

17 *Corresponding Author: xuqing.liu@manchester.ac.uk; Tel.: +44 (0) 1613064125 


\section{Abstract}

19 Water pollution from the fashion industries containing dyes has become a major source of water 20 pollution. These anthropogenic contaminated waters directly enter irrigation and drinking water

21 systems, causing irreversible environmental damage to human health. Nanomembrane technology 22 has attracted extensive attention to remove these toxic chemicals but new approaches are still 23 required for improving removal efficiency and control the channel size. The work deals with the 24 fabrication of a novel hybrid polyvinylidene fluoride (PVDF)-polyaniline (PANI) membrane with 25 graphene oxide (GO). Incorporation of PANI-GO as a nanofiller has significantly improved 26 antifouling properties and a solvent content of the fabricated membrane. Besides, pure water flux 27 also increases from 112 to $454 \mathrm{mLm}^{-2} \mathrm{~h}^{-1}$ indicating the hydrophilic nature of the nanocomposite 28 membrane. Among various compositions, the nanocomposites membrane with $0.1 \% \mathrm{w} / \mathrm{v}$ GO 29 demonstrated a maximum of $98 \%$ dye rejection at $0.1 \mathrm{MPa}$ operating pressure. After multiple

30 testing of the membrane, the flux recovery ratio reached about $94 \%$ and dyes rejection improved 31 with the addition of PANI-GO. The removal efficiency of the composite membrane for Allura red 32 is $98 \%$ and for methyl orange is $95 \%$. Based on the above results the PVDF/PANI/GO membranes 33 are recommended for practical use in wastewater treatment, particularly for anionic dyes removal 34 from textile effluents.

36 Keywords: dyes, nano-filtration, membranes, phase inversion, antifouling, wastewater, textile 37 industry 


\section{Introduction}

Water is the basic need of every living organism present on earth. Humans require water for drinking, agriculture, washing, and other purposes. Freshwater present on earth is greatly affected by the pollution caused by different activities. This wastewater includes municipal wastewater, agricultural wastewater, and industrial wastewater. Industrial wastewater is more hazardous for the ecosystem because it includes dissolved salts, chemicals, and other organic and inorganic compounds along with insoluble particles [1]. Hazardous environmental pollution, health issues, and waste of water resources occur due to the direct discharge of wastewater. For the protection of our ecosystem, harmless treatments have great importance in removing the effluent from wastewater. Dyeing and printing processes in textile industries are major causes of surface water pollution, so this problem needs attention for a long time. The effluents from dyes and printing process into the rivers and streams create a lot of issues [2]. Water becomes unsuitable for domestic and industrial purposes due to an increase in the concentration of dyes and pigments. It also affects the transmittance of light which limits the growth of aquatic plants and reduces self-purification processes. Our aquatic ecosystem is also adversely affected by textile effluents [3]. Due to complex molecular structures of textile dyes, it's difficult to remove colors by conventional treatment methods (e.g. bleaching, ozonation, hydrogen peroxide/UV, and electrochemical techniques) [4]. They are stable to light, oxidizing agents, and aerobic digestion. Numerous new methods for elimination of dyes from textile effluents are exposed and they are more beneficial than the conventional treatment methods with the advancement of discipline and technology [5]. These include reverse osmosis (RO) [6], Ultra-filtration (UF) [7] and Nano-filtration (NF) [8]. Nowadays, ultrafiltration is more valuable because of its effective performance in the purification of pollutants from wastewater [9].

In the field of material sciences, Polyvinylidene fluoride (PVDF) ultrafiltration membranes have attained great attention due to their specific properties such as membrane-forming, antioxidation activity, excellent aging resistance [10], thermal stability, high mechanical strength, and good chemical resistance properties [11]. Hao Wu et al prepared modified $\mathrm{PVDF} / \mathrm{SiO}_{2}$ membranes by using the phase inversion method. Results showed that PVDF has good thermal stability, chemical resistance, high mechanical strength and improves the antifouling properties of the membrane with the addition of $\mathrm{SiO}_{2}$ [12]. Alicia Kyoungjin et al developed modified PVDF/PDMS blend membranes for the removal of dyes. Results indicated that this membrane can be used for the treatment of negatively charged dyes [13]. But the hydrophobic nature of the PVDF makes it liable for contamination through the organic compound that decreases the water flux due to an increase of fouling within the membrane [14]. To overcome this problem several methods (chemical grafting, physical blending, surface modification, etc.) have been introduced to minimize the hydrophobic nature of the pure PVDF membrane. Physical blending is a widely used method due to superficial preparation through the phase inversion process. Ahmad et al prepared the blends membrane of Polysulfone and $\mathrm{SiO}_{2}$ nanoparticles through the phase inversion method that has the highest pure water flux, large pore size, and the high antifouling properties [15]. Liu et al also prepared blended $\mathrm{PVDF} / \mathrm{Al}_{2} \mathrm{O}_{3}$ membranes through phase inversion method. Results from SEM 
analysis indicated that $\mathrm{Al}_{2} \mathrm{O}_{3}$ improve the surface of the composite membrane [16]. By using this

79 method, various inorganic materials $\left(\mathrm{Al}_{2} \mathrm{O}_{3}, \mathrm{ZrO}_{2}, \mathrm{ZnO}, \mathrm{Fe}_{2} \mathrm{O}_{3}\right.$, and $\left.\mathrm{TiO}_{2}\right)$ were introduced in the

80 PVDF membrane to improve their properties such as hydrophilicity, higher specific surface area,

81 photocatalytic activity, bactericidal and self-cleaning, etc. Yuliwati et al prepared modified PVDF

82 membranes by using the phase inversion method. Results showed that the pore size and

83 hydrophilicity of the $\mathrm{PVDF} / \mathrm{TiO}_{2} / \mathrm{LiCl}$ membrane was affected by $\mathrm{TiO}_{2}$ and monohydrate lithium

84 chloride. The flux and permeability of the modified membrane was also improved [17]. Hamid et

85 al prepared the composite membrane of Polysulfone and $\mathrm{TiO}_{2}$ nanoparticles through phase

86 inversion method for removal of humic acid. The composite membrane has the highest pure water

87 flux and antifouling properties. Results show that this membrane can be used for $90 \%$ removal of

88 humic acid [18]. The results indicated that high concentration of inorganic materials show negative

89 effect on the elasticities and morphologies of pure PVDF filtration membranes. Due to this, it is

90 important to identify such kind of (inorganic) materials that enhance the strength of membrane and

91 also enhances hydrophilic properties of the pure PVDF membrane. Table 1 shows the polymer

92 composite membranes of the previously reported works for removal of different contaminants

93 from wastewater.

94 Table 1. Polymer membranes for wastewater treatment

\begin{tabular}{|c|c|c|c|c|c|}
\hline $\begin{array}{l}\text { Polymer } \\
\text { membrane }\end{array}$ & $\begin{array}{l}\text { Method of } \\
\text { Preparation }\end{array}$ & Remarks & $\begin{array}{l}\text { Membrane } \\
\text { performance }\end{array}$ & $\begin{array}{l}\text { Rate of } \\
\text { Rejection }\end{array}$ & Reference \\
\hline PVDF/LiCI & $\begin{array}{l}\text { Phase inversion } \\
\text { process }\end{array}$ & $\begin{array}{l}\text { Flat-sheet } \\
\text { unsupported } \\
\text { membrane }\end{array}$ & $\begin{array}{l}\text { Salt } \\
\text { Removal }\end{array}$ & $98 \%$ & [19] \\
\hline $\begin{array}{l}\text { PVDF/ } \\
\text { Acetone }\end{array}$ & Electrospinning & $\begin{array}{l}\text { Nonwoven } \\
\text { composite } \\
\text { membrane }\end{array}$ & $\begin{array}{l}\text { Separation } \\
\text { of water-in- } \\
\text { oil emulsion }\end{array}$ & $90 \%$ & [20] \\
\hline $\begin{array}{l}\mathrm{PVDF} / \mathrm{TiO}_{2-}- \\
\mathrm{PDA}\end{array}$ & $\begin{array}{l}\text { Free radical } \\
\text { polymerization }\end{array}$ & $\begin{array}{l}\text { Flat-sheet } \\
\text { hybrid } \\
\text { membrane }\end{array}$ & $\begin{array}{l}\text { Excellent } \\
\text { antifouling } \\
\text { properties }\end{array}$ & -- & [21] \\
\hline $\mathrm{PVDF} / \mathrm{H}_{3} \mathrm{PO}_{4}$ & Electrospinning & $\begin{array}{l}\text { Flat-sheet } \\
\text { composite } \\
\text { membranes }\end{array}$ & Desalination & $91 \%$ & [22] \\
\hline $\begin{array}{l}\mathrm{PVDF} / \mathrm{TiO}_{2} / \\
\mathrm{PVP}\end{array}$ & $\begin{array}{l}\text { Phase inversion } \\
\text { via dry-jet wet } \\
\text { spin method }\end{array}$ & $\begin{array}{l}\text { Hollow fibre } \\
\text { membrane }\end{array}$ & $\begin{array}{l}\text { Degradation } \\
\text { of dyes } \\
\text { molecule }\end{array}$ & $84 \%$ & [23] \\
\hline $\begin{array}{l}\text { PVDF/ } \\
\text { Cellulose/ } \\
\text { Ionic liquid }\end{array}$ & $\begin{array}{l}\text { Electrospinning } \\
\text { with surface } \\
\text { coating }\end{array}$ & $\begin{array}{l}\text { Superoleopho } \\
\text { bic composite } \\
\text { membrane }\end{array}$ & $\begin{array}{l}\text { Oil/water } \\
\text { separation }\end{array}$ & $91 \%$ & [24] \\
\hline $\begin{array}{l}\text { PVDF/PVDF- } \\
\text { g-POEM }\end{array}$ & $\begin{array}{l}\text { Atom transfer } \\
\text { radical } \\
\text { polymerization } \\
\text { (ATRP) }\end{array}$ & $\begin{array}{l}\text { Thin film } \\
\text { nano } \\
\text { composite } \\
\text { membranes }\end{array}$ & $\begin{array}{l}\text { Textile } \\
\text { wastewater } \\
\text { treatment }\end{array}$ & $71 \%$ & [25] \\
\hline
\end{tabular}




\begin{tabular}{|c|c|c|c|c|c|}
\hline $\begin{array}{l}\mathrm{PVDF} / \mathrm{PAN} / \\
\mathrm{PVA}\end{array}$ & $\begin{array}{l}\text { Extrusion } \\
\text { method }\end{array}$ & $\begin{array}{l}\text { Tubular } \\
\text { membrane }\end{array}$ & $\begin{array}{l}\text { Photocatalyt } \\
\text { ic } \\
\text { degradation }\end{array}$ & -- & [26] \\
\hline PVDF-g-PVP & $\begin{array}{l}\text { De-fluorination } \\
\text { of double bond } \\
\text { hydration with } \\
\text { graft } \\
\text { polymerization }\end{array}$ & $\begin{array}{l}\text { Macro void } \\
\text { hybrid } \\
\text { membranes } \\
\text { with high } \\
\text { porosity }\end{array}$ & $\begin{array}{l}\text { oily } \\
\text { wastewater } \\
\text { treatment }\end{array}$ & $94 \%$ & [27] \\
\hline $\begin{array}{l}\text { PVDF- } \\
\mathrm{TiO}_{2} / \mathrm{Al}_{2} \mathrm{O}_{3}\end{array}$ & $\begin{array}{l}\text { Phase inversion } \\
\text { method }\end{array}$ & $\begin{array}{l}\text { Ultra-thin } \\
\text { porous layer } \\
\text { and } \\
\text { asymmetric } \\
\text { structure }\end{array}$ & $\begin{array}{l}\text { Removal of } \\
\text { heavy } \\
\text { metals }\end{array}$ & $89 \%$ & [28] \\
\hline
\end{tabular}

96 Graphene oxide is one of attractive (inorganic) materials due to its high surface area, hydrophilic 97 nature, chemical inertness, electronic insulation properties, mechanical stability, and excellent 98 tensile modulus. Wang et al prepared the poly(vinylidene fluoride) (PVDF)/GO composite 99 membrane through phase inversion method which shows excellent hydrophilicity, high water flux 100 and good antifouling properties [29]. GO is good for the preparation of organic-inorganic blended 101 ultrafiltration membranes due to the presence of the carboxylic and hydroxyl groups in graphene 102 oxide. Polyaniline (PANI) offered suitable substitutes for conventional hydrophilicity due to its 103 special properties such as good adsorption, excellent steric hindrance, easy preparation, 104 nontoxicity, and availability as active functional groups that have interactions with PVDF and GO 105 during membrane casting.

106 To the best of our knowledge, this is the first attempt to synthesize the tri-component 107 PANI/PVDF/GO composite nanofiltration membrane. Both PANI and GO will significantly 108 improve the antifouling and dye rejection properties and demonstrate great prospects for textile 109 wastewater treatment. Current research work is mainly focusing on the development of a 110 composite membrane to efficiently remove dyes from wastewater. In this context, pristine PVDF 111 and PANI/PVDF/GO composite nanofiltration membranes were manufactured by using phase 112 inversion method. The developed membranes were tested by a series of characterization techniques 113 including scanning electron microscopy (SEM), X-ray diffraction (XRD), Tensile strength, 114 Fourier-transform infrared spectroscopy (FTIR) and thermogravimetric analysis (TGA). 115 Thereafter, the prepared PVDF/PANI/GO membranes were used to investigate properties of the 116 membrane such as porosity, shrinkage ratio, solvent content, pure water flux and retention 117 efficiency of bovine serum albumin (BSA). The effect of GO and PANI on the structure, 118 performance, and efficiency of the PVDF membrane was also characterized. 


\section{Experimental}

\subsection{Materials}

121

122

Chemicals including poly (vinylidene fluoride) (PVDF) (-CH2CF2-) (Alfa Aesar), polyaniline emeraldine salt (PANI) (MW 10000) (Sigma-Aldrich), N, N-Dimethyl formamide (DMF) (99.5\%) (Wako), N, N-dimethylacetamide (DMAc) (97+\%) (Wako), Sulphuric acid $\left(\mathrm{H}_{2} \mathrm{SO}_{4}\right)(95-$ 98\%) (Wako), 1-propanol $\left(\mathrm{C}_{3} \mathrm{H}_{8} \mathrm{O}\right)(99.5 \%)$ (Wako), Hydrogen peroxide $\left(\mathrm{H}_{2} \mathrm{O}_{2}\right)(30-35 \%)$ (Wako), Potassium permanganate $\left(\mathrm{KMnO}_{4}\right)(99+\%)$ (Sigma aldrich), Sodium hydroxide $(\mathrm{NaOH})$ 126 (98.5\%) (Fischer scientific), Acetic Acid $\left(\mathrm{CH}_{3} \mathrm{COOH}\right)$ (99+\%) (Wako), Graphite powder 127 (99.99\%) (Sigma-Aldrich), Ethanol $\left(\mathrm{C}_{2} \mathrm{H}_{5} \mathrm{OH}\right)$ (99.5+\%) (Wako), and Sodium Nitrate $\left(\mathrm{NaNO}_{3}\right)$ 128 (99\%) (Wako) were used as received.

$129 \quad 2.2 \quad$ Synthesis of graphene oxide (GO)

$130 \mathrm{GO}$ was prepared by chemical oxidation and physical exfoliation [30]. Briefly, $2 \mathrm{~g}$ of graphite 131 powder was added to $46 \mathrm{ml}$ of conc. $\mathrm{H}_{2} \mathrm{SO}_{4}$ under continuous stirring followed by the addition of $1321 \mathrm{~g} \mathrm{NaNO}_{3}$ in $500 \mathrm{ml}$ beaker placed in an iced bath over a hot plate magnetic stirrer. Afterward, 6 $133 \mathrm{~g}$ of $\mathrm{KMnO}_{4}$ was added to the mixture under constant stirring and the temperature was raised to $13420^{\circ} \mathrm{C}$. The reaction mixture was left under stirring until a thick dark paste was obtained. The 135 temperature of the hot plate was further raised to $90^{\circ} \mathrm{C}$, while adding $100 \mathrm{ml}$ of distill water to the 136 reaction mixture. The reaction mixture was continuously stirred at $90^{\circ} \mathrm{C}$ under dropwise addition 137 of $10 \mathrm{ml} \mathrm{H}_{2} \mathrm{O}_{2}$. Finally, a dark brown solution was obtained which was washed with distilled water 138 to neutralize. The mixture was filtered, and the cake obtained was washed with 1:10 $\mathrm{HCl}$ for the removal of metal ions. The mixture was again washed with distilled water for the removal of acid traces and again filtered to get a solid cake. The filtered cake was dispersed in distilled water and ultra-sonicated to exfoliate the GO. The unexfoliated GO was removed by centrifugation at 3000

$142 \mathrm{rpm}$ for $20 \mathrm{~min}$. The GO powder was obtained by drying the exfoliated GO in a vacuum oven 143 overnight at $60^{\circ} \mathrm{C}$.

\section{$144 \quad 2.3 \quad$ Synthesis of PVDF-PANI-GO composite membranes}

145 Composite membranes were fabricated by using the phase inversion method. PANI and GO were 146 used as additives to increase the hydrophilicity and filtration properties of PVDF membranes. 147 PVDF ( $12 \% \mathrm{w} / \mathrm{v})$, PANI ( $3 \% \mathrm{w} / \mathrm{v})$ and GO $(0.05 \%, 0.1 \%, 0.5 \%, 1 \% \mathrm{w} / \mathrm{v})$ were dissolved to DMF 148 and the solution was stirred for 24 hours at $59^{\circ} \mathrm{C}$. The mixture was heated in a water bath at $40{ }^{\circ} \mathrm{C}$ 149 under constant mechanical stirring in a covered beaker for 0.5 hours to swell the polymers. Then 150 the temperature of the water bath was raised to $70^{\circ} \mathrm{C}$ and stirred for another 7 hours to completely 151 dissolve the polymers. Solutions were kept at $50^{\circ} \mathrm{C}$ in an oven for at least 6 hours to get rid of any 152 air bubble. The obtained clear solutions were cast on to a glass substrate through a hand coating 153 device equipped with a doctor blade and it was immediately dipped in a coagulation bath 154 containing deionized water at $25^{\circ} \mathrm{C}$ [31]. After the phase inversion process, the developed 155 membranes were further held overnight in fresh distilled water to extract the remaining solvent 156 entrapped in the prepared PVDF/PANI/GO composite membrane. Fig.1. gives the schematic for 
157 the development of the membranes by the phase inversion method. The compositions and codes 158 for different samples are listed in Table 2.

159 Table 2. Code of Pure PVDF, PVDF-PANI and PVDF-PANI-GO composite membranes.

\begin{tabular}{cccccc}
\hline Code & $\begin{array}{c}\text { PVDF } \\
(\mathbf{w} / \mathbf{v} \%)\end{array}$ & $\begin{array}{c}\text { PANI } \\
(\mathbf{w} / \mathbf{v} \%)\end{array}$ & $\begin{array}{c}\text { GO } \\
(\mathbf{w} / \mathbf{v} \%)\end{array}$ & $\begin{array}{c}\text { DMF } \\
(\mathbf{w} / \mathbf{v} \%)\end{array}$ & $\begin{array}{c}\text { Total conc. } \\
(\mathbf{w} / \mathbf{v} \%)\end{array}$ \\
\hline 0P & 12 & 3 & 0 & 85.0 & 100 \\
PP & 12 & 3 & 0 & 85.0 & 100 \\
PG1 & 11.95 & 3 & 0.05 & 85.0 & 100 \\
PG2 & 11.90 & 3 & 0.1 & 85.0 & 100 \\
PG3 & 11.50 & 3 & 0.5 & 85.0 & 100 \\
PG4 & 11.00 & 3 & 1 & 85.0 & 100 \\
\hline
\end{tabular}

160

161

162

163

164

165

166

167

168

169

170

171

172

173

\subsection{Characterization}

Membranes were characterized by using XRD, FTIR, TGA, and SEM. Panalytical 3040/60 X'pert PRO diffract meter was used for XRD characterization and evaluation of structural properties of samples in the range of $0^{\circ}$ to $80^{\circ}$. FTIR spectrum was obtained by 1000 Perkin Elmer in the range of $500-4000 \mathrm{~cm}^{-1}$, which was used for functional group analysis. TGA/DT Perkin-Elmer, USA was used for thermal gravimetric analysis i.e. the determination of the thermal stability of pristine and composite membranes. The surface morphology and cross-section of the PVDF/PANI/GO membranes and pure PVDF filtration membrane was analyzed by using FEG FEI SEM (Tescan Mira3 SC) with an accelerating voltage of $10 \mathrm{kV}$.

\subsection{Membrane permeation performances}

\subsubsection{Porosity}

A piece of the membrane was cut into a square of $1 \mathrm{~cm}^{2}$ and it was immersed in deionized water for one day [32]. The weight of the membrane was measured before and after wetting. The following formula was used for the calculation of porosity.

$$
\text { Porosity } \%=\frac{W_{2}-W_{1} / \rho \mathrm{w}}{\mathrm{w}_{1} / \rho \mathrm{w}\left(W_{2}-W_{1}\right) / \rho \mathrm{w}} \times 100
$$

$174 \mathrm{~W}_{1}$ and $\mathrm{W}_{2}$ is the weight before and after wetting, and $\rho \mathrm{w}$ is the water density.

175

176

177

178

179

180

181

\subsubsection{Solvent content}

A piece of the membrane was cut into a square of $1 \mathrm{~cm}^{2}$ and it was immersed in different organic solvents such as propanol, ethanol, water, and methanol for one day. The weight of the membrane was measured before and after wetting. The following formula was used for calculating solvent content [33].

$$
\text { Solvent Content } \%=\frac{\mathrm{W}_{2}-\mathrm{W}_{1}}{\mathrm{~W}_{2}} \times 100
$$

$\mathrm{W}_{1}$ and $\mathrm{W}_{2}$ is the weight before and after wetting respectively. 


\subsubsection{Shrinkage ratio}

183 A piece of the membrane was cut into a square of $1 \mathrm{~cm}^{2}$. Vernier caliper and screw gauge were 184 used to measure its length and thickness, then the membrane was immersed into water for 12 hours 185 and its length and width were calculated again. The following formula was used for calculation 186 [23].

\subsubsection{Pure water flux}

191 The vacuum filtration pump was used for the calculation of pure water flux. For permeation experiments, the membranes were immersed in water for one day. Trans-membrane pressure $(0.1$ $\mathrm{MPa}$ ) was applied to developed membranes for 30 minutes. Pure water flux of the developed sample membranes was calculated at $25^{\circ} \mathrm{C}$ for every one-minute time interval. The following formula [34] was used for calculation of pure water flux;

$$
\text { Pure Water Flux }(J)=\frac{\mathrm{Q}}{\mathrm{At}}
$$

197 Symbols t for time, A for the membrane area in $\mathrm{cm}$ and Q for the amount of water that passes 198 through a membrane in 1 minute $(t)$ is used.

\subsubsection{Antifouling property}

For the calculation of antifouling property of the composite membrane bovine serum albumin (BSA) was used, which is one of the model proteins for the investigation of the antifouling nature of membranes. The aqueous solution of BSA $\left(0.8 \mathrm{~g} \mathrm{~L}^{-1}\right)$ was used in a filtration cell that follows the initial pure water flux (Jw1) measurement. Filtration of the BSA solution was done by using the samples of membrane for 30 minutes at $0.1 \mathrm{MPa}$ trans-membrane pressure. Then, the membrane was fouled and washed with water for 30 minutes, after which flux (Jw2) ( $\mathrm{L} \mathrm{m}^{-2} \mathrm{~h}^{-1}$ ) was calculated again [35]. Following formula was used for evaluation of the flux recovery ratio;

$$
\mathrm{FRR} \%=\frac{\mathrm{J}_{\mathrm{W}}}{\mathrm{J}_{2} 2} \times 100
$$

Rejection (percent) of BSA [36]was calculated using the formula,

$$
\% \mathrm{R}=\left(1-\frac{\mathrm{C}_{\mathrm{P}}}{\mathrm{C}_{\mathrm{f}}}\right) \times 100
$$

$\mathrm{C}_{\mathrm{p}}$ and $\mathrm{C}_{\mathrm{f}}$ are the molarity of permeate and feeds BSA solution, respectively.

The molarity of feed and permeate BSA containing solution at $\lambda_{\max }=280 \mathrm{~nm}$ was analyzed by the UV-VIS spectrophotometer. 
215 The removal experiments of methyl orange (MO) and allura red (AR) was carried out under 216 vacuum filtration. UV-VIS spectrophotometer (DR5000, Hach) was used to determine the removal of dyes in the sample solution. The concentration of dyes in the sample solution was detected by the maximum absorbance wavelength $\left(\lambda_{\max }\right)$ in the UV-VIS spectrometer. Dye rejection was calculated 219 by using the formula,

$$
\% \mathrm{R}=\left(1-\frac{\mathrm{C}_{\mathrm{P}}}{\mathrm{C}_{\mathrm{f}}}\right) \times 100
$$

$\mathrm{C}_{\mathrm{p}}$ and $\mathrm{C}_{\mathrm{f}}$ are the molarity of permeate and feed of dye solutions, respectively. The calibration curve for methyl orange $\left(\lambda_{\max }=464 \mathrm{~nm}\right)$ and allura red $\left(\lambda_{\max }=505 \mathrm{~nm}\right)$ are given in Fig. 2 . The solutions were analysed against standard fitted plots; $(y=-0.4247+9.716 x$ for MO), and $(y=-$ $0.7404+23.80 \mathrm{x}$ for allura red) to determine the percentage dye removal from the wastewater samples.

\subsubsection{Adsorption study}

The adsorption studies toward anionic dye were carried out by using MO as the model dye to determine the adsorption capacity of the PVDF/PANI/GO composite membrane. The experiments were conducted within a set of $150 \mathrm{~mL}$ flasks which contain PVDF/PANI/GO composite membrane $(0.6 \mathrm{~g})$ and $50.0 \mathrm{~mL}$ solution of MO. The samples were kept in an isothermal water-bath for 90.0 minutes at the temp of $298 \mathrm{~K}$. UV-VIS spectrophotometer (DR5000, Hach) was used to measure initial and remaining concentrations of MO. By dye adsorption experiments, we also determine the effect of different parameters such as time (0-25 hours), $\mathrm{pH}(4.5-9.5)$, and effect of dye concentration (MO) $(25.0-200 \mathrm{mg} / \mathrm{L})$.

The value of the adsorption $\left(\mathrm{q}_{\mathrm{e}}\right)$ was measured by using following equation [37]:

$$
\text { Adsorption }(\mathrm{qe})=\frac{(\mathrm{Co}-\mathrm{Ce}) \mathrm{V}}{\mathrm{m}}
$$

The concentration of $\mathrm{MO}$ at initial and equilibrium point represented by $\mathrm{C}_{\mathrm{o}}$ and $\mathrm{C}_{\mathrm{e}}(\mathrm{mg} / \mathrm{L})$, respectively; $\mathrm{V}$ is volume; and $\mathrm{m}$ is the mass of composite membrane. For $\mathrm{pH}$-dependent experiments, $0.01 \mathrm{M} \mathrm{HNO3}$ or $0.01 \mathrm{M} \mathrm{NaOH}$ solutions were used to adjust the $\mathrm{pH}$ in the range (4.5-9.5) of the $\mathrm{MO}$ solution $(100 \mathrm{mg} / \mathrm{L})$ [38]. In kinetic adsorption experiments, $0.6 \mathrm{~g}$ of $\mathrm{PVDF} / \mathrm{PANI} / \mathrm{GO}$ composite membranes were dipped into different concentrations of MO solution and taken out after certain time intervals.

For the adsorption isotherm experiments, PVDF/PANI/GO composite membranes were dipped into the solution of MO $(100 \mathrm{mg} / \mathrm{L})$. The same process was repeated at different temperatures (298 $\mathrm{K}, 308 \mathrm{~K}$, and $318 \mathrm{~K}$ ). The value of adsorption (qt) after time t, was calculated using the following equation [39]:

$$
\text { Absorption }(\mathrm{qt})=\frac{(\mathrm{Co}-\mathrm{Ct}) \mathrm{V}}{\mathrm{m}}
$$

The concentration of $\mathrm{MO}$ at initial and equilibrium point represented by $\mathrm{C}_{o}$ and $\mathrm{C}_{t}(\mathrm{mg} / \mathrm{L})$, respectively; $\mathrm{V}$ is volume, and $\mathrm{m}$ is the mass of the composite membrane. The detailed study with results and discussion was explained in supporting information. 


\section{Results and Discussion}

252

253

254

255

256

257

258

259

260

261

262

263

264

265

266

267

268

269

270

271

272

273

274

275

276

277

278

279

280

281

282

283

284

285

286

287

288

289

290

291

292

293

294

\subsection{SEM analysis of PVDF/PANI/GO composite membranes}

The morphology of pure PVDF membrane and effect of PANI and GO on membranes surface was analyzed by scanning electron microscopy. Fig. 3 (1a-6a) shows SEM micrographs of pure PVDF and composite membrane's surface that contains PANI (hydrophilic polymer) and various concentrations of graphene oxide (PP, PG1, PG2, PG3, PG4). From the SEM images, it can be observed that there is an increase in roughness and asymmetry of composite membranes due to the addition of graphene oxide. This increase in asymmetry and roughness causes an increase in hydrophilicity and pure water flux of membrane. The enhancement in roughness can also be due to the nucleation and growth of polymer after incorporation of PANI. The surface of composite membranes also shows a 'pit-like' structure [40]. For geometric analysis of these membranes, structure of porous membrane has been regenerated through software (ImageJ) from SEM images of membrane [41]. The corresponding estimations of pores diameter and distributions of pores on these membrane's surfaces shown in Fig.3 (1b-6b). We can clearly see that in pure PVDF membrane number of pores are less but with addition of the filler (PANI and GO) content, the number of pores increased. The average diameter of pores also decreases with the addition of PANI and GO [42]. The pristine PVDF membrane has an average pore diameter of around $1.53 \mu \mathrm{m}$ while pores in composite membranes (PP, PG1, PG2, PG3, and PG4) have an average diameter of about $0.78 \mu \mathrm{m}, 0.34 \mu \mathrm{m}, 0.09 \mu \mathrm{m}, 0.03 \mu \mathrm{m}$ and $0.01 \mu \mathrm{m}$ respectively. The reduction in pore size is the result of complex structure formation due to good chemical interaction of the PVDF with filler content (PANI-GO).

A cross-sectional analysis of pure membranes was also performed by using SEM. Fig. 3 (1c-6c) shows cross-sectional images of pure PVDF and PVDF/PANI/GO composite membranes. All synthesized membranes have good miscibility of polymers and graphene oxide, so they do not show any phase separation. The cross-section of the membrane contains about $100 \mu \mathrm{m}$ thickness with asymmetric morphology. SEM analysis of pure PVDF membrane (a) revealed asymmetric pores structure with a dense layer on top of the membrane. The dense layer on the upper side formed due to the faster phase inversion process of PVDF in the coagulation bath. With the introduction of fillers (PANI/GO) content, these membranes become more porous and uniform distribution of the pores can be seen within composite membranes. SEM analysis also represents that the number of pores increases with the addition of the filler content, but excessive GO may penetrate in the pores and reduced their amount. Fig. $3(5 \mathrm{c})$ and $(6 \mathrm{c})$ represent that filler (GO) content of $0.1 \% \mathrm{w} / \mathrm{v}$ is suitable but after that excessive $\mathrm{GO}$ can block the pores and reduce the pure water flux of (PG3, PG4) membranes [43].

\subsection{Physicochemical analysis of the PVDF/PANI/GO composite membranes}

XRD analysis in Fig. 4 (a) illustrates the diffractograms of the GO, Pure PVDF, PVDF/PANI and $\mathrm{PVDF} / \mathrm{PANI} / \mathrm{GO}$ composite membranes. It is expected that the graphite show two characteristic peaks at $26^{\circ}$ and $55^{\circ}$ corresponding to the lattice planes (002 and 004) [44]. After oxidation, these reported peaks shift towards smaller angles. The diffractogram of the GO which shows only (002) plane peak at $10^{\circ}$. The presence of the peak at $10^{\circ}$ confirms the efficiency of the oxidation process due to an increase in the planar distance between graphene nanoplatelets upon the insertion of oxygen groups. Thus the peak at $2 \theta=10^{\circ}$ is an expected one for the oxygenated groups in the GO due to an increase in the interplanar distance [45]. The pure PVDF spectra show its characteristic $\alpha$-phase crystalline peaks at $18.08^{\circ}$ and $19.7^{\circ}$ [46]. Polyaniline and GO are both amorphous and 
hence will show similar effects individually as well as in combination [47]. The GO peak disappears in the composite membranes, which confirms the fine dispersion of the GO within the composite. As reported by Gascho et al that when GO was vacuum filtered the XRD pattern started to show peaks other than at $10^{\circ}$, due to partial restacking of the graphene oxide [45]. In composite membranes, the $\alpha$-phase peaks at $18.08^{\circ}$ disappear due to the crystal transformation of PVDF. Moreover, composite membranes exhibit a new diffraction peak at $20.5^{\circ}$, which corresponds to the (110) and (200) planes of $\beta$-phase. The formation of $\beta$-polymorph can be due to interaction between the carbonyl groups $(-\mathrm{C}=\mathrm{O})$ present in $\mathrm{GO}$ and the $\mathrm{CF}_{2}$ segments in PVDF polymer. There is a similar pattern of XRD shown for different concentrations of graphene oxide but a very little shift in the position of hump can be observed with increasing concentration of graphene oxide.

The presence of $\beta$-phase in PVDF/PANI/GO nanocomposite membranes was further confirmed by FTIR analysis. Fig. 4 (b) shows the FT-IR spectra of pure PVDF and membranes blended with the PANI and GO at four different concentrations $(0.05 \%, 0.1 \%, 0.5 \%, 1 \% \mathrm{w} / \mathrm{v})$. There are some similar peaks in the spectra of all membranes relating to the characteristic peaks of PVDF; Peaks at the $612 \mathrm{~cm}^{-1}$ are assigned to $\mathrm{CF}_{2}$ bending, $793 \mathrm{~cm}^{-1}$ correspond to $\mathrm{CH}_{2}$ group and $976 \mathrm{~cm}^{-1}$ represent the out of plane deformation of the $\mathrm{CH}$ group. All these peaks represent the $\alpha$-phase of the PVDF membrane. While the peaks at 1271, 1077, and $840 \mathrm{~cm}^{-1}$ represent $\beta$-phase of the composite membrane. The FT-IR spectra of membranes containing additives reveal an extra broad peak comparing with the pure PVDF membrane at around $1411 \mathrm{~cm}^{-1}$ for N-H bending, peaks at the $871 \mathrm{~cm}^{-1}$ are assigned to aromatic ring present in the polyaniline. The peaks at $1252 \mathrm{~cm}^{-1}$ correspond to the $-\mathrm{C}-\mathrm{N}$ stretching mode of the benzenoid ring. The transmittance peak at $2359 \mathrm{~cm}^{-1}$ was attributed to C-O carbonyl stretching in the GO skeleton. What's more, the absorption peak at $1180 \mathrm{~cm}^{-1}$ was attributed to the stretching vibration of $\mathrm{CO}$ groups. XRD and FTIR analysis represent that there is no significant difference between the different concentrations of GO in the composite membrane. It represents that each membrane has GO nanosheets which contain enough carbonyl group to nucleate the chain of PVDF into $\beta$-phase.

\subsection{Thermal and mechanical stability of PVDF/PANI/GO composite membrane}

The thermal behavior of the composite membrane was studied through Thermo Gravimetric Analysis (TGA). TGA of pure PVDF and PANI/PVDF/GO composite membranes with variable concentration of GO i.e. $0.05 \% \mathrm{w} / \mathrm{v}$ to $1 \% \mathrm{w} / \mathrm{v}$ are displayed in Table 3 and Fig. 5 (a). On heating the membranes from $35^{\circ} \mathrm{C}$ to $800^{\circ} \mathrm{C}$, pure PVDF membrane and PVDF/PANI blend membrane show the considerable weight loss in comparison to the composite membranes with GO. Thermal decomposition of the composite increased from $398^{\circ} \mathrm{C}$ to $470^{\circ} \mathrm{C}$ [48]. This increase in temperature demonstrates the thermal stability of the composites. It establishes the fact that the thermal stability of the composites increases as the concentration of GO is increased from $0.05 \% \mathrm{w} / \mathrm{v}$ to $1 \% \mathrm{w} / \mathrm{v}$. Also, as the concentration of GO increases, the interfacial interactions between the PVDF and PANI also enhances due to the presence of a functional group in graphene oxide. 
Table 3. TGA calculated parameters of pure PVDF, PVDF/PANI and PVDF/PANI/GO composite membranes.

\begin{tabular}{cccccc}
\hline \multirow{2}{*}{ Codes } & Td & \multicolumn{3}{c}{ Temperature at: } & \multirow{2}{*}{ Residue \% } \\
\cline { 3 - 5 } & & $5 \%$ wt. loss & $\begin{array}{c}10 \% \text { wt. } \\
\text { Loss }\end{array}$ & $\begin{array}{c}\text { Max. wt. } \\
\text { Loss }\end{array}$ & \\
\hline 0P & 398 & 366 & 409 & 494 & 10 \\
PP & 460 & 460 & 490 & 495 & 12 \\
PG1 & 463 & 484 & 499 & 499 & 21 \\
PG2 & 467 & 452 & 501 & 501 & 28 \\
PG3 & 469 & 474 & 505 & 505 & 30 \\
PG4 & 470 & 370 & 507 & 507 & 31 \\
\hline
\end{tabular}

334 Tensile properties were analyzed to determine the mechanical properties of PVDF-PANI-GO 335 composites membranes. These results represent that nanocomposite membranes were stronger, but they become more brittle than pure PVDF membrane due to the addition of GO (Fig. 5 (b)). Some more important factors that involved to describe these facts are; carbon nanomaterials (GO) entangle with the polymeric chains of PVDF and PANI and provide the additional binding site for the hybrid membrane and results in an excellent interaction between $\mathrm{GO}$ and polymer chains [49]. Due to this, Young's Modulus was increased from 32.12MPa to 90.03MPa with increasing the concentration of the GO. The tensile strength of composite membranes was also increased with the addition of GO nanosheets due to their large surface area, which is one of the significant factors to enhance the interaction with polymers. The good miscibility of GO with PANI and PVDF also 344 contributes to increasing the mechanical properties of the PVDF/PANI/GO composite membrane. Tensile strength of polymer nanocomposite membranes increases with the addition of GO from $0.05 \% \mathrm{w} / \mathrm{v}$ to $0.1 \% \mathrm{w} / \mathrm{v}$, but further increase in the concentration of GO from $0.1 \% \mathrm{w} / \mathrm{v}$ to $1 \% \mathrm{w} / \mathrm{v}$ causes enough brittleness in membranes to break them easily and thus reduces the tensile strength [50].

\subsection{Membrane permeation properties of PVDF/PANI/GO composite membrane}

The porosity of all different composite membranes was calculated by measuring their wet and dry weight with water density. The results of membrane porosity are summarized in Fig. 6 (a). Fig. 6 (a) illustrates that there is a continuous increase in the porosity of the PVDF/PANI/GO composite membrane with an increase in the concentration of GO from 0 to $0.1 \% \mathrm{w} / \mathrm{v}$. This increase in porosity can be explained by the hydrophilic nature of GO content which results in increased porosity. But when the concentration of graphene is increased from $0.1 \% \mathrm{w} / \mathrm{v}$ to $1 \% \mathrm{w} / \mathrm{v}$, the porosity decreased because the excess amount of graphene oxide may block the pores of the membrane. Porosity had also a great influence on the \% shrinkage ratio. With an increase in 
porosity, shrinkage ratio decreases because it increases the hydrophilicity of the membrane. The results for the \% shrinkage ratio are also shown graphically in Fig. 6 (a). From Fig. 6 (a), it is clear that the $\%$ shrinkage ratio is decreased as the concentration of filler (GO) is increased. The shrinkage ratio is found less than $15 \%$ in these membranes and this ratio is found to be more effective.

For determination of the nature of the membranes, four different solvents were selected according to the polarity of the solvent. These solvents were arranged in decreasing order of polarity from water to Propanol. To check out the solvent absorption of the composite membrane, $1 \mathrm{~cm}^{2}$ of each composite membrane was dipped into the different solvents like water, ethanol, methanol, and propanol for 24 hours. The solvent content was calculated by the weight difference of the dry and wet membrane. It showed that water content increased with increasing the filler content (GO) due to this improved hydrophilicity of the composite membrane which may enhance the water permeability by attracting water molecules inside the membrane and facilitating them to pass through the membrane. After investigating the solvent content of these membranes, the results are given in Fig. 6 (b).

Pure water flux (PWF) was calculated before and after the addition of the hydrophilic additive at the pressure of $0.1 \mathrm{MPa}$. The influence of the graphene oxide content on the performance of PVDF/PANI membranes has been illustrated in Fig. 6 (c). The pure water flux of PVDF/PANI/GO composite membrane increased dramatically with PANI content, the water flux also increases with the addition of graphene oxide $(0.05 \mathrm{w} / \mathrm{v}$ to $1 \% \mathrm{w} / \mathrm{v})$ but further increase in the concentration of graphene oxide causes blockage of pores of the membrane which results in a decrease of pure water flux [51].

\subsection{Hydrophilic properties of PVDF/PANI/GO composite membrane}

The hydrophilicity of the blend and composite membrane surface has been determined through the contact angle measurement. It plays a significant role in increasing the pure water flux and antifouling properties of the membrane. Hydrophilicity is better when the contact angle of the membrane is smaller. Furthermore, on the upper surface of the hydrophilic membrane, water from the compact layer repels the organic deposition on the membranes to improve their antifouling properties. Such an increase in hydrophilicity is beneficial to reduce membrane fouling, especially organic fouling. The hydrophilic and more wettable surface layer typically yields better water permeability and fouling resistance in water purification applications [52]. During the phase inversion method, graphene oxide migrates on the upper surface of the membrane and form it hydrophilic. This is supported by a decrease in contact angle of composite membranes then pure PVDF membrane.

Fig. 7 (a) illustrates that the contact angle decreased from $90^{\circ}$ to $56^{\circ}$ with the addition of the filler content (GO) which shows that the hydrophilicity of the membrane has been improved. PVDF is one of the hydrophobic matrix, which contributes to the hydrophobic nature of the pure PVDF membrane, but the addition of polyaniline induces the - $\mathrm{NH}$ group on the surface of the membrane which has the tendency for hydrogen binding and results in decreased contact angle and thus 
improved hydrophilicity of the membrane [53]. GO nano-sheets contain large number of the $-\mathrm{OH}$ groups responsible for increased hydrophilicity of membrane [54]. Fig. 7 (b) represent the contact angle measurement after every four seconds to calculate the water permeation properties of synthesized membranes. These results show that GO content within the membrane decreases the age of drop and increases the pure water flux.

\subsection{Performance of PVDF/PANI/GO composite membranes for removal of dye}

404 Filtration properties of synthesized membrane were calculated by preparation of two type of dyes solutions with 100ppm concentration of allura red and methyl orange into the deionized water. Fig. 8 represent the dye rejection properties of pure PVDF (OP) and composite membranes (PP, PG1and PG2). The dyes were passed through membranes with $0.1 \mathrm{MPa}$ pressure. All membranes show dye rejection due to the sieving nature and adsorption behavior of porous membranes [55]. The molecular weight of dyes also affects the dye rejection rate, when we used the same membranes to calculate their performance, the rejection rate slightly increased with an increase in the molecular weight of dyes [56]. The dye rejection properties of PG3 and PG4 membranes cannot be evaluated because their high crystallinity and brittleness make them so fragile that they break on applying pressure of 0.1MPa. Fig. 8 (a) and (b) illustrates that the graphene oxide and polyaniline composite membrane has a higher percentage of dye rejection about $95 \%$ for methyl orange and $98 \%$ for allura red in comparison to the pure PVDF membrane. Composite membranes contain the smaller pore size than the hydrodynamic diameter of dyes molecules, so the sieving mechanism of membrane controls the flow of dyes through it. Moreover, the dye flux for pristine PVDF membrane is about $23 \mathrm{~L} \mathrm{~m}^{-2} \mathrm{~h}^{-1}$, while for composite membranes (PP, PG1, and PG2) flux is about 58,62 and $65 \mathrm{~L} \mathrm{~m}^{-2} \mathrm{~h}^{-1}$ respectively. Fig. 8 also shows that the removal efficiency of membrane for AR was slightly better than MO due to the different structure and high molecular weight of allura red $(496.42 \mathrm{~g} / \mathrm{mol})$ than methyl orange $(327.33 \mathrm{~g} / \mathrm{mol})$ [57]. Fig. 8 (c) and (d) illustrates the UV analysis of the permeate solution of methyl orange and allura red from all membranes. As filler content (PANI-GO) was increased, the absorbance values of permeate solutions becomes low due to better ability of nanocomposite membranes to remove the dyes. For reproducibility, all experiments were conducted three times, and mean results were presented with standard deviation. Table 4 gives a comparison of the dye rejection rate and water flux of the previously reported work.

428 Table 4. Comparison of the dye rejection rate and water flux of the previously reported literature.

\begin{tabular}{llllllll}
\hline $\begin{array}{l}\text { Filtration } \\
\text { Membrane }\end{array}$ & $\begin{array}{l}\text { Method of } \\
\text { Preparation }\end{array}$ & Dye & $\begin{array}{l}\text { Pure water } \\
\text { flux }\left(\mathbf{L ~ m}^{-2} \mathbf{h}^{-}\right. \\
\left.\mathbf{1}^{\mathbf{1}}\right)\end{array}$ & $\begin{array}{l}\text { Contact } \\
\text { angle }\end{array}$ & $\begin{array}{l}\text { Rate of } \\
\text { Dye } \\
\text { Rejectio } \\
\mathbf{n}(\%)\end{array}$ & $\begin{array}{l}\text { Referen } \\
\text { ces }\end{array}$ \\
\hline $\begin{array}{l}\text { Polypropylene } \\
\text { PVA }\end{array}$ & $\begin{array}{l}\text { Dip coating } \\
\text { method }\end{array}$ & $\begin{array}{l}\text { Victoria } \\
\text { blue (B) }\end{array}$ & 118.73 & 62.43 & 91.2 & {$[58]$}
\end{tabular}




\begin{tabular}{|c|c|c|c|c|c|c|}
\hline $\begin{array}{l}\mathrm{PVC} / \mathrm{TiO} 2 \\
\text { /Al2O3 }\end{array}$ & -- & $\begin{array}{l}\text { Erichrom } \\
\text { e black T }\end{array}$ & 165 & 86 & $>99$ & [59] \\
\hline $\begin{array}{l}\mathrm{PES} / \mathrm{PEG} / \mathrm{PV} \\
\mathrm{P}\end{array}$ & $\begin{array}{l}\text { One step } \\
\text { electro } \\
\text { spinning }\end{array}$ & $\begin{array}{l}\text { Indigo } \\
\text { carmine }\end{array}$ & 212.80 & -- & 96 & [60] \\
\hline $\begin{array}{l}\text { Poly(p- } \\
\text { phenylene } \\
\text { sulfide /GO }\end{array}$ & $\begin{array}{l}\text { Solution } \\
\text { casting }\end{array}$ & $\begin{array}{l}\text { Methylen } \\
\text { e blue }\end{array}$ & 325.65 & 54 & 94.2 & [61] \\
\hline PS/PES & $\begin{array}{l}\text { Interfacial } \\
\text { polymerization }\end{array}$ & $\begin{array}{l}\text { Reactive } \\
\text { dyes }\end{array}$ & 35.43 & -- & 90.9 & [62] \\
\hline $\begin{array}{l}\text { PVDF/Tetrah } \\
\text { ydrofuran }\end{array}$ & $\begin{array}{l}\text { Phase } \\
\text { inversion } \\
\text { free radical }\end{array}$ & $\begin{array}{l}\text { Methyl } \\
\text { orange }\end{array}$ & 171.80 & 75 & 80.3 & [63] \\
\hline $\begin{array}{l}\text { PAN/ } \\
\text { Chitosan }\end{array}$ & $\begin{array}{l}\text { graft } \\
\text { copolymerizati } \\
\text { on }\end{array}$ & $\begin{array}{l}\text { Crystal } \\
\text { violet }\end{array}$ & 229.82 & 84 & 89.04 & [64] \\
\hline $\begin{array}{l}\text { Sulfated } \\
\text { polyelectrolyt } \\
\text { e/ Chitosan }\end{array}$ & $\begin{array}{l}\text { Solution } \\
\text { casting }\end{array}$ & $\begin{array}{l}\text { Reactive } \\
\text { orange } 16\end{array}$ & 110.32 & 72 & 90.9 & [65] \\
\hline $\begin{array}{l}\text { Polyamide } \\
\text { /carboxyl- } \\
\text { functionalized } \\
\text { graphene } \\
\text { oxide }\end{array}$ & $\begin{array}{l}\text { Interfacial } \\
\text { polymerization }\end{array}$ & $\begin{array}{l}\text { New } \\
\text { Coccine }\end{array}$ & 311.02 & 89.32 & 95 & [66] \\
\hline $\begin{array}{l}\text { PVDF/PANI/ } \\
\text { GO }\end{array}$ & $\begin{array}{l}\text { Phase } \\
\text { inversion }\end{array}$ & $\begin{array}{l}\text { Methyl } \\
\text { orange } \\
\text { and } \\
\text { Allura } \\
\text { red }\end{array}$ & 454 & 56.11 & 98 & $\begin{array}{l}\text { This } \\
\text { Work }\end{array}$ \\
\hline
\end{tabular}

\subsubsection{Effect of dyes concentration on membrane performance}

431 Film Theory equation [67] proves that dyes concentration of feed solution has a significant effect

432 on the performance of nanofiltration membranes. Five series of experiments were conducted to 433 find out the effect of different concentrations (50,100, 200, 400, 800ppm) of dye (Methyl orange) 434 on membrane flux and dye rejection. According to Fig. 9 (a), dye flux of pure PVDF and composite 435 membranes were gradually declined with increasing the concentrations of dye (50 to 800ppm) in 436 the feed solution. As the concentration of dye increases, dye molecules deposit and aggregate onto 437 the surface of the membrane that causes polarization and increased osmotic pressure within the 438 membranes [68]. Moreover, these aggregates might block the pores of the membrane surface by 439 adsorption that cause membrane fouling. Therefore, the flux of OP, PP, PG1, and PG2 were 440 decreased by $25.1 \%, 18.9 \% .16 .1 \%$ and $10.2 \%$ respectively. PG2 showed a very slight decline in 441 dye flux due to better antifouling properties of the composite membrane [69]. According to Fig. 9 
442 (b), an increase in the concentration of dye in feed solution also has a significant effect on dye 443 rejection. The dye removal efficiency of the composite membrane (PG2) was least affected and 444 show a high rejection rate of about $98 \%$.

\section{$445 \quad 3.7$ Antifouling properties and BSA rejection of PVDF/PANI/GO composite membranes}

446 The particles and solutes deposit on the surface of the membrane and into the pores of the membrane cause membrane fouling and decline in flux during the filtration process [70]. Although the membrane fouling is unavoidable, it can be decreased by adopting suitable strategies such as the use of hydrophilic material within the membrane. In this work, the addition of PANI and GO to the casting solution results in increase in hydrophilicity of membrane and decreases its fouling. Antifouling properties of membranes were evaluated by using BSA as the model fouling agent. The relative pure water flux (PWF) was calculated before and after the filtration of the BSA solution and reported as the flux recovery ratio [71]. Fig. 10(a) show that the pure PVDF membrane was not effective for BSA rejection (39\%) due to its hydrophobic nature but with the addition of PANI (PP) and graphene oxide (PG1, PG2) rejection rate was increased to about $73 \%$, $76 \%, 78 \%$ respectively [72].

To check the reusability and anti-fouling properties of membranes, dye wastewater (methyl orange solution) was used as a fouling agent. The contaminated membranes were washed with HCL solution for 30 minutes after every cycle to remove the fouling agent from the membrane surface and then their performance was investigated [73]. These antifouling testing were only performed on 0P, PP, PG1, and PG2 because PG3 and PG4 were not suitable for the filtration process due to their excessive brittleness. Fig. 10 (b) show that flux of all membranes was reduced with the passage of time due to the adsorption of dye molecules on membrane surface that cause pore blockage of the membrane. After cleaning through HCL for a half-hour, membranes show favorable recovery in dye flux of all membranes. Fig. 10 (c) represents that the flux recovery ratio of composite membranes (PP, PG1, and PG2) was higher as compared to the pure PVDF membrane after three cycles. Long term dye flux of membranes is shown in Fig. 10 (d). The flux of all membranes was declined with the passage of time but PG2 shows a less decline than other membranes. This is due to good hydrophilic properties of GO and PANI in composite membrane surface [74]. Such membranes repel the hydrophobic contaminants from their surface during the filtration process. So PG2 show excellent anti-fouling properties for practical applications. Based on the results, PVDF/PANI/GO composite membranes have great potential for the treatment of textile effluents particularly dyes. They outperform the previously used nanofiltration membranes considering the water flux and dye rejection properties, indicative of superiority to deal with textile wastewater. In order to demonstrate the superiority of developed PVDF-PANIGO composite membranes in real applications, the key results and significant parameters of these membranes were compared with commercially available PVDF membranes. The results demonstrate that the pure water flux of our novel membrane $\left(454 \mathrm{~L} \mathrm{~m}^{-2} \mathrm{~h}^{-1}\right)$ is higher than commercial pure PVDF membrane $\left(252 \mathrm{~L} \mathrm{~m}^{-2} \mathrm{~h}^{-1}\right)$ [75]. The commercially available PVDF membrane is only useful for microfiltration but our novel PVDF-PANI-GO membrane can also be 
used for nanofiltration of pollutants due to their smaller pore size $(0.09 \mu \mathrm{m})$. The PVDF membrane is hydrophobic in nature with higher contact angle $\left(118.3^{\circ}\right)$, so organic contaminants can foul the surface of this membrane whereas the hydrophilic nature of the novel PVDF-PANI-GO composite membrane due to it lower contact angle $\left(56.11^{\circ}\right)$ illustrate its better antifouling properties [76]. The result of recycling tests also indicates that the developed nanocomposite membranes possesses good long-term stability in the nanofiltration process. Therefore, these novel membranes provide a new route to remove dyes from textile wastewater. The performance of PVDF-PANI-GO composite membranes were found to better than established technologies under same conditions (Table 4).

In future, focus could be to improve the dye removal capability of novel PVDF-PANI-GO composite membranes to make them more competitive. Further, these membranes could be coupled with biological treatment technologies to develop single integrated system in order to improve efficiency of effluents removal and reduce energy consumption. There is also a potential of collaboration with industrial partners to test real water samples and improve their reusability up to 3-5 years for scaling up and introduce it as a commercial product.

\section{Conclusion}

498 In this research article, we described the synthesis GO by using modified Hummer's method and its integration in pure PVDF and the composite PVDF/PANI/GO membrane by using the phase inversion method. The optimized amount of GO for wastewater treatment membrane is $0.1 \% \mathrm{w} / \mathrm{v}$, if we further increase the concentration of GO, membranes become brittle and reduces the number of pores in composite membrane. Considering the morphological and structural evidence of membranes, we reached the following conclusions;

1. PVDF based membrane containing PANI and GO have smaller shrinkage ratio and pore size with excessive roughness of membrane surface than pure PVDF membrane. This indicates that fillers improve the permeation properties of composite membranes.

2. The hydrophilicity of membranes enhances with the addition of GO and PANI. The contact angle decreased from $90.32^{\circ}$ to $56.11^{\circ}$, which describes the presence of oxygenated and hydroxyl functional groups of graphene oxide on the surface of the composite membrane.

3. Pure water flux of composite membrane enhances from 112 to $454 \mathrm{~L} \mathrm{~m}^{-2} \mathrm{~h}^{-1}$. Graphene oxide also improved the BSA rejection in the pure PVDF membrane from $38.6 \%$ to $78.32 \%$.

4. Thermal and mechanical stability improves with the addition of $2 \mathrm{D}$ material in the pristine membrane. Degradation temperature was increased from $398^{\circ} \mathrm{C}$ to $470^{\circ} \mathrm{C}$ with the addition of GO and PANI in the PVDF membrane. The Young's Modulus and tensile strength of composite membranes also improved from $32 \mathrm{MPa}$ to $90 \mathrm{MPa}$.

5. After multiple testing of the membrane, the flux recovery ratio reached about $94 \%$ and dyes rejection improved with the addition of GO and PANI content. The removal efficiency of the composite membrane for allura red is $98 \%$ and for methyl orange is $95 \%$. 


\section{References}

520 [1] J. Zuo, S. Bonyadi, T.S. Chung, Exploring the potential of commercial polyethylene

[4] H. Razzaq, H. Nawaz, A. Siddiqa, M. Siddiq, S. Qaisar, A Brief Review on Nanocomposites based on PVDF with Nanostructured TiO2 as Filler, Madridge J. Nanotechnol. Nanosci. 1 (2016) 22-28. https://doi.org/10.18689/mjnn-1000107.

[5] G. Zuo, R. Wang, Novel membrane surface modification to enhance anti-oil fouling property for membrane distillation application, J. Memb. Sci. 447 (2013) 26-35. https://doi.org/10.1016/j.memsci.2013.06.053.

[6] Z. Chen, D. Rana, T. Matsuura, Y. Yang, C.Q. Lan, Study on the structure and vacuum membrane distillation performance of PVDF composite membranes: I. Influence of blending, Sep. $\quad$ Purif. $\quad$ Technol. $133 \quad$ (2014) 303-312. https://doi.org/10.1016/j.seppur.2014.07.015.

[7] L. Eykens, I. Hitsov, K. De Sitter, C. Dotremont, L. Pinoy, I. Nopens, B. Van der Bruggen, Influence of membrane thickness and process conditions on direct contact membrane distillation at different salinities, J. Memb. Sci. 498 (2016) 353-364. https://doi.org/10.1016/j.memsci.2015.07.037.

[8] D. Hou, G. Dai, H. Fan, J. Wang, C. Zhao, H. Huang, Effects of calcium carbonate nanoparticles on the properties of PVDF/nonwoven fabric flat-sheet composite membranes for direct contact membrane distillation, Desalination. 347 (2014) 25-33. https://doi.org/10.1016/j.desal.2014.05.028.

[9] K. Farahbakhsh, C. Svrcek, R.K. Guest, D.W. Smith, A review of the impact of chemical pretreatment on low-pressure water treatment membranes, J. Environ. Eng. Sci. 3 (2004) 237-253. https://doi.org/10.1139/S03-078.

[10] M.R. Moghareh Abed, S.C. Kumbharkar, A.M. Groth, K. Li, Economical production of PVDF-g-POEM for use as a blend in preparation of PVDF based hydrophilic hollow fibre membranes, $\quad$ Sep. $\quad$ Purif. $\quad$ Technol. $106 \quad$ (2013) 47-55. https://doi.org/10.1016/j.seppur.2012.12.024.

[11] T. Malik, H. Razzaq, S. Razzaque, H. Nawaz, A. Siddiqa, M. Siddiq, S. Qaisar, Design and synthesis of polymeric membranes using water-soluble pore formers: an overview, Polym. Bull. 76 (2019) 4879-4901. https://doi.org/10.1007/s00289-018-2616-3. 
[12] $\mathrm{H} . \mathrm{Wu}, \mathrm{J}$. Mansouri, V. Chen, Silica nanoparticles as carriers of antifouling ligands for PVDF ultrafiltration membranes, J. Memb. Sci. 433 (2013) 135-151. https://doi.org/10.1016/j.memsci.2013.01.029.

562

563

564

565

566

567

568

569

570

571

572

573

574

575

576

577

578

579

580

581

582

583

584

585

586

587

588

589

590

591

592

593

594

595

596

597

598

13] I. Type, A. Kyoungjin, L. E-j, I. License, PDMS / PVDF hybrid electrospun membrane with superhydrophobic property and drop impact dynamics for dyeing wastewater treatment using membrane distillation Author's Accepted Manuscript, (2019).

[14] A. Razmjou, E. Arifin, G. Dong, J. Mansouri, V. Chen, Superhydrophobic modification of TiO 2 nanocomposite PVDF membranes for applications in membrane distillation, J. Memb. Sci. 415-416 (2012) 850-863. https://doi.org/10.1016/j.memsci.2012.06.004.

[15] A.L. Ahmad, M.A. Majid, B.S. Ooi, Functionalized PSf/SiO2 nanocomposite membrane for oil-in-water emulsion separation, Desalination. 268 (2011) 266-269. https://doi.org/10.1016/j.desal.2010.10.017.

[16] F. Liu, M.R.M. Abed, K. Li, Preparation and characterization of poly(vinylidene fluoride) (PVDF) based ultrafiltration membranes using nano $\gamma$-Al2O3, J. Memb. Sci. 366 (2011) 97-103. https://doi.org/10.1016/j.memsci.2010.09.044.

[17] E. Yuliwati, A.F. Ismail, Effect of additives concentration on the surface properties and performance of PVDF ultrafiltration membranes for refinery produced wastewater treatment, Desalination. 273 (2011) 226-234. https://doi.org/10.1016/j.desal.2010.11.023.

[18] N.A.A. Hamid, A.F. Ismail, T. Matsuura, A.W. Zularisam, W.J. Lau, E. Yuliwati, M.S. Abdullah, Morphological and separation performance study of polysulfone/titanium dioxide (PSF/TiO2) ultrafiltration membranes for humic acid removal, Desalination. 273 (2011) 85-92. https://doi.org/10.1016/j.desal.2010.12.052.

[19] M. Tomaszewska, Preparation and properties of flat-sheet membranes from poly(vinylidene fluoride) for membrane distillation, Desalination. 104 (1996) 1-11. https://doi.org/10.1016/0011-9164(96)00020-3.

[20] Z. Zhou, X.F. Wu, Electrospinning superhydrophobic-superoleophilic fibrous PVDF membranes for high-efficiency water-oil separation, Mater. Lett. 160 (2015) 423-427. https://doi.org/10.1016/j.matlet.2015.08.003.

[21] X. Zhao, Y. Su, Y. Liu, R. Zhang, Z. Jiang, Multiple antifouling capacities of hybrid membranes derived from multifunctional titania nanoparticles, J. Memb. Sci. 495 (2015) 226-234. https://doi.org/10.1016/j.memsci.2015.08.026.

[22] D. Hou, G. Dai, J. Wang, H. Fan, L. Zhang, Z. Luan, Preparation and characterization of $\mathrm{PVDF} /$ nonwoven fabric flat-sheet composite membranes for desalination through direct contact membrane distillation, Sep. Purif. Technol. 101 (2012) 1-10. https://doi.org/10.1016/j.seppur.2012.08.031.

[23] C.S. Ong, W.J. Lau, P.S. Goh, B.C. Ng, T. Matsuura, A.F. Ismail, Effect of PVP Molecular Weights on the Properties of PVDF-TiO2 Composite Membrane for Oily Wastewater Treatment Process, Sep. Sci. Technol. $49 \quad$ (2014) 2303-2314. https://doi.org/10.1080/01496395.2014.928323.

[24] F. Ejaz Ahmed, B.S. Lalia, N. Hilal, R. Hashaikeh, Underwater superoleophobic 
cellulose/electrospun PVDF-HFP membranes for efficient oil/water separation, Desalination. 344 (2014) 48-54. https://doi.org/10.1016/j.desal.2014.03.010.

[25] A. Akthakul, R.F. Salinaro, A.M. Mayes, Antifouling polymer membranes with subnanometer size selectivity, Macromolecules. 37 (2004) 7663-7668. https://doi.org/10.1021/ma048837s.

[26] K. Karakulski, W.A. Morawski, J. Grzechulska, Purification of bilge water by hybrid ultrafiltration and photocatalytic processes, Sep. Purif. Technol. 14 (1998) 163-173. https://doi.org/10.1016/S1383-5866(98)00071-9.

[27] X. Huang, W. Wang, Y. Liu, H. Wang, Z. Zhang, W. Fan, L. Li, Treatment of oily waste

[28] X.S. Yi, S.L. Yu, W.X. Shi, S. Wang, N. Sun, L.M. Jin, X. Wang, L.P. Sun, Hydrodynamics https://doi.org/10.1016/j.cej.2015.03.086.

behaviour of oil field wastewater advanced treatment by ultrafiltration process, Desalination. 305 (2012) 12-16. https://doi.org/10.1016/j.desal.2012.06.012.

[29] Z. Wang, H. Yu, J. Xia, F. Zhang, F. Li, Y. Xia, Y. Li, Novel GO-blended PVDF ultrafiltration membranes, Desalination. 299 (2012) 50-54. https://doi.org/10.1016/j.desal.2012.05.015.

[30] M. Sohail, M. Saleem, S. Ullah, N. Saeed, A. Afridi, M. Khan, M. Arif, Modified and improved Hummer's synthesis of graphene oxide for capacitors applications, Mod. Electron. Mater. 3 (2017) 110-116. https://doi.org/10.1016/j.moem.2017.07.002.

[31] L. Zheng, J. Wang, J. Li, Y. Zhang, K. Li, Y. Wei, Preparation, evaluation and modification of PVDF-CTFE hydrophobic membrane for MD desalination application, Desalination. 402 (2017) 162-172. https://doi.org/10.1016/j.desal.2016.10.003.

[32] M. Baghbanzadeh, D. Rana, T. Matsuura, C.Q. Lan, Effects of hydrophilic CuO nanoparticles on properties and performance of PVDF VMD membranes, Desalination. 369 (2015) 75-84. https://doi.org/10.1016/j.desal.2015.04.032.

[33] T. Iqbal, R. Sahrash, A. Siddiqa, S. Afsheen, M.B. Tahir, M.I. Khan, K.N. Riaz, G. Nabi, M. Fahad, M. Sharif, M. Abrar, Preparation and characterization of polyvinylidene fluoride/1-butyl-3-methylimidazolium bromide-based ionogel membranes for desalination applications, Int. J. Environ. Sci. Technol. 16 (2019) 7081-7092. https://doi.org/10.1007/s13762-019-02207-8.

[34] J. Du, Y. Tian, N. Li, J. Zhang, W. Zuo, Enhanced antifouling performance of $\mathrm{ZnS} / \mathrm{GO} / \mathrm{PVDF}$ hybrid membrane by improving hydrophilicity and photocatalysis, Polym. Adv. Technol. 30 (2019) 351-359. https://doi.org/10.1002/pat.4472.

[35] S. Goh, J. Zhang, Y. Liu, A.G. Fane, Fouling and wetting in membrane distillation (MD) and MD-bioreactor (MDBR) for wastewater reclamation, Desalination. 323 (2013) 39-47. https://doi.org/10.1016/j.desal.2012.12.001.

[36] Y. Orooji, E. Ghasali, N. Emami, F. Noorisafa, A. Razmjou, ANOVA design for the optimization of TiO2 coating on polyether sulfone membranes, Molecules. 24 (2019) 1-13. https://doi.org/10.3390/molecules24162924. 
[37] L. Chen, Y. Li, Q. Du, Z. Wang, Y. Xia, E. Yedinak, J. Lou, L. Ci, High performance agar/graphene oxide composite aerogel for methylene blue removal, Carbohydr. Polym. 155 (2017) 345-353. https://doi.org/10.1016/j.carbpol.2016.08.047.

[38] Y. Li, Q. Du, T. Liu, J. Sun, Y. Wang, S. Wu, Z. Wang, Y. Xia, L. Xia, Methylene blue adsorption on graphene oxide/calcium alginate composites, Carbohydr. Polym. 95 (2013) 501-507. https://doi.org/10.1016/j.carbpol.2013.01.094.

[39] X. Wei, T. Huang, J. hui Yang, N. Zhang, Y. Wang, Z. wan Zhou, Green synthesis of hybrid graphene oxide/microcrystalline cellulose aerogels and their use as superabsorbents, J. Hazard. Mater. 335 (2017) 28-38. https://doi.org/10.1016/j.jhazmat.2017.04.030.

[40] T.T. Van Tran, S.R. Kumar, S.J. Lue, Separation mechanisms of binary dye mixtures using a PVDF ultrafiltration membrane: Donnan effect and intermolecular interaction, J. Memb. Sci. 575 (2019) 38-49. https://doi.org/10.1016/j.memsci.2018.12.070.

[41] X.L. Cao, Y.N. Yan, F.Y. Zhou, S.P. Sun, Tailoring nanofiltration membranes for effective removing dye intermediates in complex dye-wastewater, J. Memb. Sci. 595 (2020). https://doi.org/10.1016/j.memsci.2019.117476.

[42] L. Yan, S. Hong, M.L. Li, Y.S. Li, Application of the Al2O3-PVDF nanocomposite tubular ultrafiltration (UF) membrane for oily wastewater treatment and its antifouling research, Sep. Purif. Technol. 66 (2009) 347-352. https://doi.org/10.1016/j.seppur.2008.12.015.

[43] O. Benhabiles, F. Galiano, T. Marino, H. Mahmoudi, H. Lounici, A. Figoli, Preparation and characterization of TiO2-PVDF/PMMA blend membranes using an alternative non-toxic solvent for UF/MF and photocatalytic application, Molecules. 24 (2019) 1-20. https://doi.org/10.3390/molecules24040724.

[44] S. Peng, X. Fan, S. Li, J. Zhang, Green synthesis and characterization of graphite oxide by orthogonal experiment, J. Chil. Chem. Soc. 58 (2013) 2213-2217. https://doi.org/10.4067/S0717-97072013000400067.

[45] J.L.S. Gascho, S.F. Costa, A.A.C. Recco, S.H. Pezzin, Graphene Oxide Films Obtained by Vacuum Filtration: X-Ray Diffraction Evidence of Crystalline Reorganization, J. Nanomater. 2019 (2019) 1-12. https://doi.org/10.1155/2019/5963148.

[46] N. Meng, R.C.E. Priestley, Y. Zhang, H. Wang, X. Zhang, The effect of reduction degree of GO nanosheets on microstructure and performance of PVDF/GO hybrid membranes, J. Memb. Sci. 501 (2016) 169-178. https://doi.org/10.1016/j.memsci.2015.12.004.

[47] A.L. Ahmad, U.R. Farooqui, N.A. Hamid, Synthesis and characterization of porous poly(vinylidene fluoride-co-hexafluoro propylene) (PVDF-co-HFP)/poly(aniline) (PANI)/graphene oxide (GO) ternary hybrid polymer electrolyte membrane, Electrochim. Acta. 283 (2018) 842-849. https://doi.org/10.1016/j.electacta.2018.07.001.

[48] Y. Zhang, Y. Peng, S. Ji, Z. Li, P. Chen, Review of thermal efficiency and heat recycling in membrane distillation processes, Desalination. 367 (2015) 223-239. https://doi.org/10.1016/j.desal.2015.04.013.

[49] J. Zuo, T.S. Chung, G.S. O’Brien, W. Kosar, Hydrophobic/hydrophilic PVDF/Ultem ${ }^{\circledR}$ dual-layer hollow fiber membranes with enhanced mechanical properties for vacuum 
membrane distillation, J. Memb. https://doi.org/10.1016/j.memsci.2016.09.030.

Sci. $\quad 523$ (2017) $103-110$.

[50] J. Zhang, Z. Xu, W. Mai, C. Min, B. Zhou, M. Shan, Y. Li, C. Yang, Z. Wang, X. Qian, Improved hydrophilicity, permeability, antifouling and mechanical performance of PVDF composite ultrafiltration membranes tailored by oxidized low-dimensional carbon nanomaterials, J. Mater. Chem. A. 1 (2013) 3101-3111. https://doi.org/10.1039/c2ta01415g.

[51] D. Sun, M.Q. Liu, J.H. Guo, J.Y. Zhang, B.B. Li, D.Y. Li, Preparation and characterization of PDMS-PVDF hydrophobic microporous membrane for membrane distillation, Desalination. 370 (2015) 63-71. https://doi.org/10.1016/j.desal.2015.05.017.

[52] X. Chang, Z. Wang, S. Quan, Y. Xu, Z. Jiang, L. Shao, Exploring the synergetic effects of graphene oxide (GO) and polyvinylpyrrodione (PVP) on poly(vinylylidenefluoride) (PVDF) ultrafiltration Membrane performance, Appl. Surf. Sci. 316 (2014) 537-548. https://doi.org/10.1016/j.apsusc.2014.07.202.

[53] X. Chen, Y. He, Y. Fan, G. Zeng, L. Zhang, Nature-inspired polyphenol chemistry to fabricate halloysite nanotubes decorated PVDF membrane for the removal of wastewater, Sep. Purif. Technol. 212 (2019) 326-336. https://doi.org/10.1016/j.seppur.2018.11.036.

[54] B.M. Ganesh, A.M. Isloor, A.F. Ismail, Enhanced hydrophilicity and salt rejection study of graphene oxide-polysulfone mixed matrix membrane, Desalination. 313 (2013) 199-207. https://doi.org/10.1016/j.desal.2012.11.037.

[55] M. Amini, M. Arami, N.M. Mahmoodi, A. Akbari, Dye removal from colored textile wastewater using acrylic grafted nanomembrane, Desalination. 267 (2011) 107-113. https://doi.org/10.1016/j.desal.2010.09.014.

[56] R. Han, S. Zhang, D. Xing, X. Jian, Desalination of dye utilizing copoly(phthalazinone biphenyl ether sulfone) ultrafiltration membrane with low molecular weight cut-off, J. Memb. Sci. 358 (2010) 1-6. https://doi.org/10.1016/j.memsci.2010.03.036.

[57] Y. Zhao, W. Yu, R. Li, Y. Xu, Y. Liu, T. Sun, L. Shen, H. Lin, Electric field endowing the conductive polyvinylidene fluoride (PVDF)-graphene oxide (GO)-nickel (Ni) membrane with high-efficient performance for dye wastewater treatment, Appl. Surf. Sci. 483 (2019) 1006-1016. https://doi.org/10.1016/j.apsusc.2019.04.054.

[58] Y. Zheng, G. Yao, Q. Cheng, S. Yu, M. Liu, C. Gao, Positively charged thin-film composite hollow fiber nanofiltration membrane for the removal of cationic dyes through submerged filtration, Desalination. 328 (2013) 42-50. https://doi.org/10.1016/j.desal.2013.08.009.

[59] P. Chen, X. Ma, Z. Zhong, F. Zhang, W. Xing, Y. Fan, Performance of ceramic nanofiltration membrane for desalination of dye solutions containing $\mathrm{NaCl}$ and $\mathrm{Na} 2 \mathrm{SO} 4$, Desalination. 404 (2017) 102-111. https://doi.org/10.1016/j.desal.2016.11.014.

[60] J. Gao, Z. Thong, K. Yu Wang, T.S. Chung, Fabrication of loose inner-selective polyethersulfone (PES) hollow fibers by one-step spinning process for nanofiltration (NF) of textile dyes, J. Memb. Sci. 541 (2017) 413-424. https://doi.org/10.1016/j.memsci.2017.07.016. 
[61] Y. Gao, K. Su, X. Wang, Z. Li, A metal-nano GO frameworks/PPS membrane with super water flux and high dyes interception, J. Memb. Sci. 574 (2019) 55-64. https://doi.org/10.1016/j.memsci.2018.12.052.

[62] X. Wei, X. Kong, C. Sun, J. Chen, Characterization and application of a thin-film composite nanofiltration hollow fiber membrane for dye desalination and concentration, Chem. Eng. J. 223 (2013) 172-182. https://doi.org/10.1016/j.cej.2013.03.021.

[63] M. Mertens, T. Van Dyck, C. Van Goethem, A.Y. Gebreyohannes, I.F.J. Vankelecom, Development of a polyvinylidene difluoride membrane for nanofiltration, J. Memb. Sci. 557 (2018) 24-29. https://doi.org/10.1016/j.memsci.2018.04.020.

[64] S. Liu, Z. Wang, P. Song, Free Radical Graft Copolymerization Strategy to Prepare Catechin-Modified Chitosan Loose Nanofiltration (NF) Membrane for Dye Desalination, ACS Sustain. Chem. $\quad$ Eng. 6 (2018) 4253-4263. https://doi.org/10.1021/acssuschemeng.7b04699.

[65] C.C. Ye, F.Y. Zhao, J.K. Wu, X.D. Weng, P.Y. Zheng, Y.F. Mi, Q.F. An, C.J. Gao, Sulfated polyelectrolyte complex nanoparticles structured nanoflitration membrane for dye desalination, Chem. Eng. J. 307 (2017) 526-536. https://doi.org/10.1016/j.cej.2016.08.122.

[66] H. Zhang, Bin Li, J. Pan, Y. Qi, J. Shen, C. Gao, B. Van der Bruggen, Carboxylfunctionalized graphene oxide polyamide nanofiltration membrane for desalination of dye solutions containing monovalent salt, J. Memb. Sci. 539 (2017) 128-137. https://doi.org/10.1016/j.memsci.2017.05.075.

[67] I. Koyuncu, D. Topacik, M.R. Wiesner, Factors influencing flux decline during nanofiltration of solutions containing dyes and salts, Water Res. 38 (2004) 432-440. https://doi.org/10.1016/j.watres.2003.10.001.

[68] N.M. Mokhtar, W.J. Lau, A.F. Ismail, W. Youravong, W. Khongnakorn, K. Lertwittayanon, Performance evaluation of novel PVDF-Cloisite 15A hollow fiber composite membranes for treatment of effluents containing dyes and salts using membrane distillation, RSC Adv. 5 (2015) 38011-38020. https://doi.org/10.1039/c5ra00182j.

[69] I. Koyuncu, Reactive dye removal in dye/salt mixtures by nanofiltration membranes containing vinylsulphone dyes: Effects of feed concentration and cross flow velocity, Desalination. 143 (2002) 243-253. https://doi.org/10.1016/S0011-9164(02)00263-1.

[70] J. Haberkamp, M. Ernst, G. Makdissy, P.M. Huck, M. Jekel, Protein fouling of ultrafiltration membranes - Investigation of several factors relevant for tertiary wastewater treatment, J. Environ. Eng. Sci. 7 (2008) 651-660. https://doi.org/10.1139/S08-038.

[71] K.J. Lu, J. Zuo, T.S. Chung, Novel PVDF membranes comprising n-butylamine functionalized graphene oxide for direct contact membrane distillation, J. Memb. Sci. 539 (2017) 34-42. https://doi.org/10.1016/j.memsci.2017.05.064.

[72] S. Gul, Z.A. Rehan, S.A. Khan, K. Akhtar, M.A. Khan, M.I. Khan, M.I. Rashid, A.M. Asiri, S.B. Khan, Antibacterial PES-CA-Ag2O nanocomposite supported $\mathrm{Cu}$ nanoparticles membrane toward ultrafiltration, BSA rejection and reduction of nitrophenol, J. Mol. Liq. 230 (2017) 616-624. https://doi.org/10.1016/j.molliq.2016.12.093. 
[73] M. Isoyama, S.I. Wada, Remediation of $\mathrm{Pb}$-contaminated soils by washing with hydrochloric acid and subsequent immobilization with calcite and allophanic soil, J. Hazard. Mater. 143 (2007) 636-642. https://doi.org/10.1016/j.jhazmat.2007.01.008.

[74] J. Lin, W. Ye, H. Zeng, H. Yang, J. Shen, S. Darvishmanesh, P. Luis, A. Sotto, B. Van der Bruggen, Fractionation of direct dyes and salts in aqueous solution using loose nanofiltration membranes, J. Memb. Sci. 477 (2015) 183-193. https://doi.org/10.1016/j.memsci.2014.12.008.

[75] J. Ji, F. Liu, N.A. Hashim, M.R.M. Abed, K. Li, Poly(vinylidene fluoride) (PVDF) membranes for fluid separation, React. Funct. Polym. 86 (2015) 134-153. https://doi.org/10.1016/j.reactfunctpolym.2014.09.023.

[76] A.K. An, J. Guo, E.J. Lee, S. Jeong, Y. Zhao, Z. Wang, T.O. Leiknes, PDMS/PVDF hybrid electrospun membrane with superhydrophobic property and drop impact dynamics for dyeing wastewater treatment using membrane distillation, J. Memb. Sci. 525 (2017) 57-67. https://doi.org/10.1016/j.memsci.2016.10.028. 


\section{$774 \quad$ List of Figures}

775 Fig. 1. Schematic representation of membrane fabrication through phase inversion method.

776 Fig. 2. Calibration curves for the (a) methyl orange and (b) allura red.

777 Fig. 3. 1(a) Surface morphology 1(b) Pore geometry analysis 1(c) Cross-sectional images of pure 778 PVDF membrane. 2(a) Surface morphology 2(b) Pore geometry analysis 2(c) Cross-sectional 779 images of PVDF/PANI membrane. 3(a) Surface morphology 3(b) Pore geometry analysis 3(c) 780 Cross-sectional images of PG1 composite membrane. 4(a) Surface morphology 4(b) Pore 781 geometry analysis 4(c) Cross-sectional images of PG2 composite membrane. 5(a) Surface 782 morphology 5(b) Pore geometry analysis 5(c) Cross-sectional images of PG3 composite 783 membrane. 6(a) Surface morphology 6(b) Pore geometry analysis 6(c) Cross-sectional images of 784 PG4 composite membrane.

785 Fig. 4. (a) X-Ray diffractogram of GO, PVDF, PVDF/PANI and PVDF/PANI/GO composite 786 membranes (b) FTIR spectra of PVDF, PVDF/PANI and PVDF/PANI/GO composite membranes.

787 Fig. 5. (a) TGA and (b) tensile properties of pure PVDF, PVDF/PANI, and PVDF/PANI/GO 788 composite membranes.

789 Fig. 6. Graphs for (a) Porosity and \% shrinkage ratio (b) Solvent content (c) Pure water flux of 790 pure PVDF, PVDF/PANI, and PVDF/PANI/GO composite membranes.

791 Fig. 7. (a) Contact angle (b) Time dependent contact angle of pure PVDF, PVDF/PANI, and $792 \mathrm{PVDF} / \mathrm{PANI} / \mathrm{GO}$ composite membranes.

793 Fig. 8. Dye rejection and flux of (a) Allura Red and (b) Methyl Orange of pure PVDF, 794 PVDF/PANI, and PVDF/PANI/GO composite membranes. UV-VIS Spectra of filtrate solution of 795 (c) Allura Red and (d) Methyl Orange through pure PVDF, PVDF/PANI, and PVDF/PANI/GO 796 composite membranes.

797 Fig. 9. Dye concentrations effect on (a) Dye flux of pure PVDF, PVDF/PANI, and 798 PVDF/PANI/GO composite membranes (b) Dye rejection (\%) of PG2 composite membrane.

799 Fig. 10. (a) BSA rejection (b) Recycling properties (c) Flux recovery ratio in each cycle (d) Dye 800 flux for long time of pure PVDF, PVDF/PANI, and PVDF/PANI/GO composite membranes. 


\section{$801 \quad$ List of Tables}

802 Table 1. Comparison of the previously reported literature.

803 Table 2. Code of Pure PVDF, PVDF-PANI and PVDF-PANI-GO composite membranes.

804 Table 3. TGA calculated parameters of pure PVDF, PVDF/PANI and PVDF/PANI/GO composite 805 membranes.

806 Table 4. Comparison of the dye rejection rate and water flux of the previously reported literature. 
Click here toaccess/download;Figure;Figures.pptx $\stackrel{\underline{\underline{*}}}{ }$

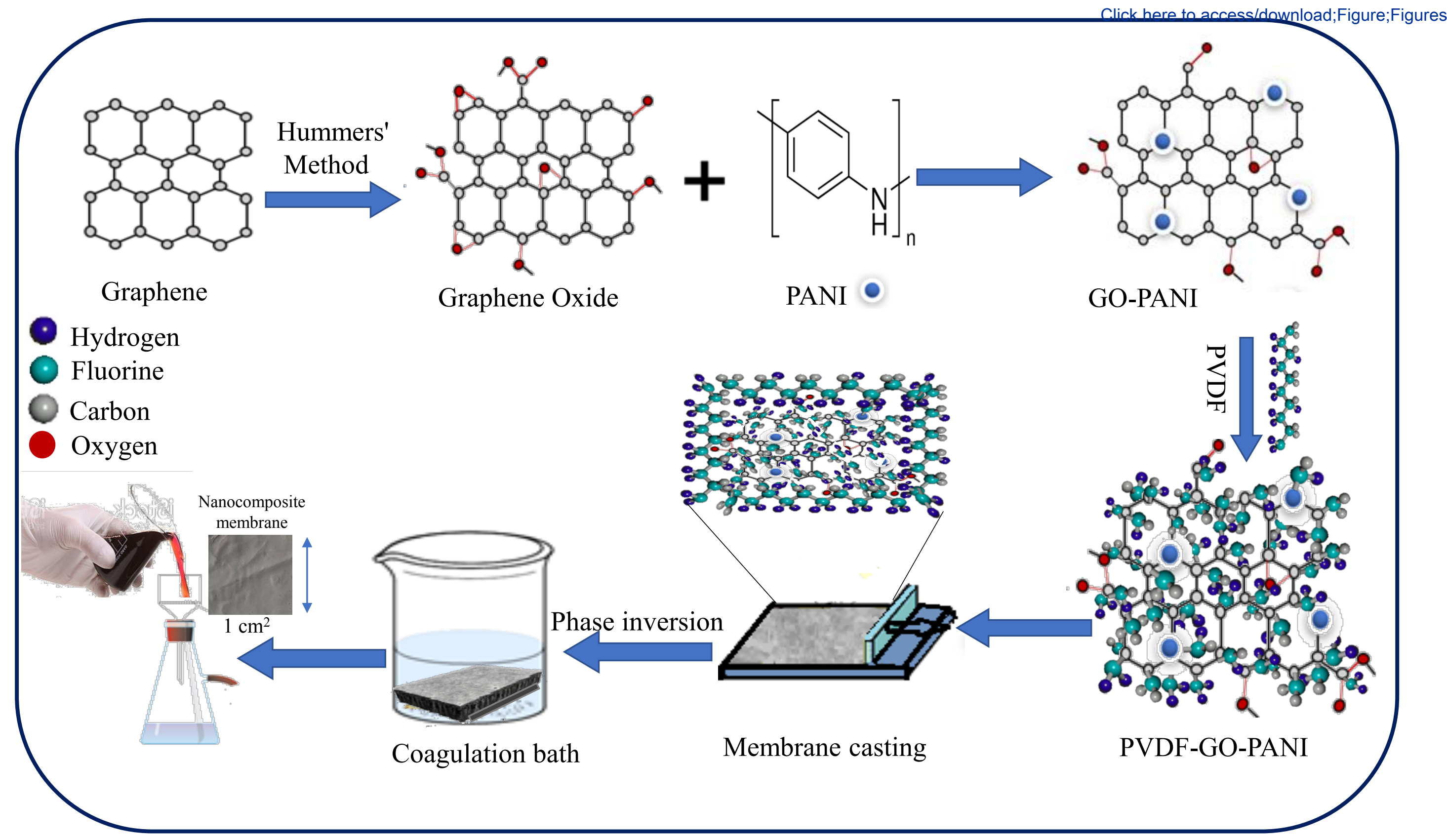

Fig. 1. Schematic representation of membrane fabrication through phase inversion method. 

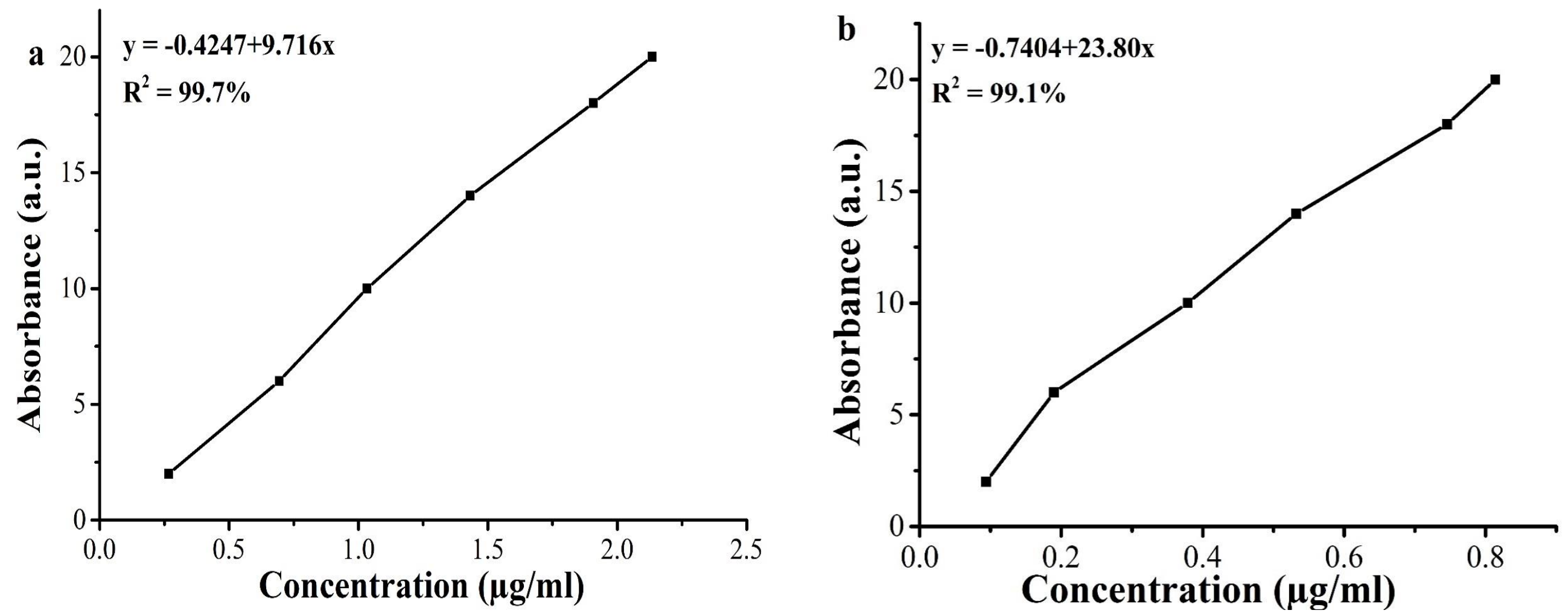

Fig. 2. Calibration curves for the (a) methyl orange and (b) allura red. 


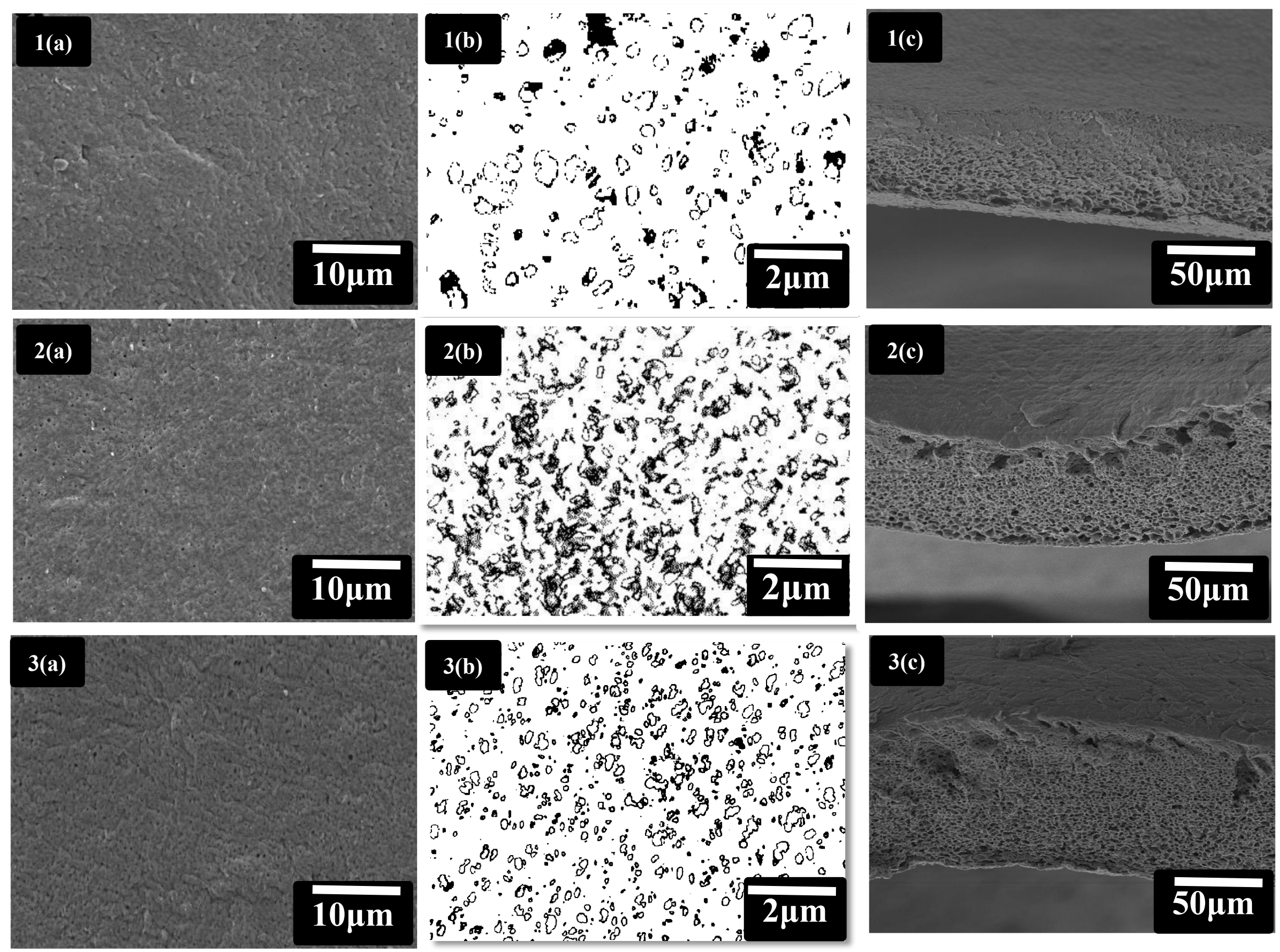



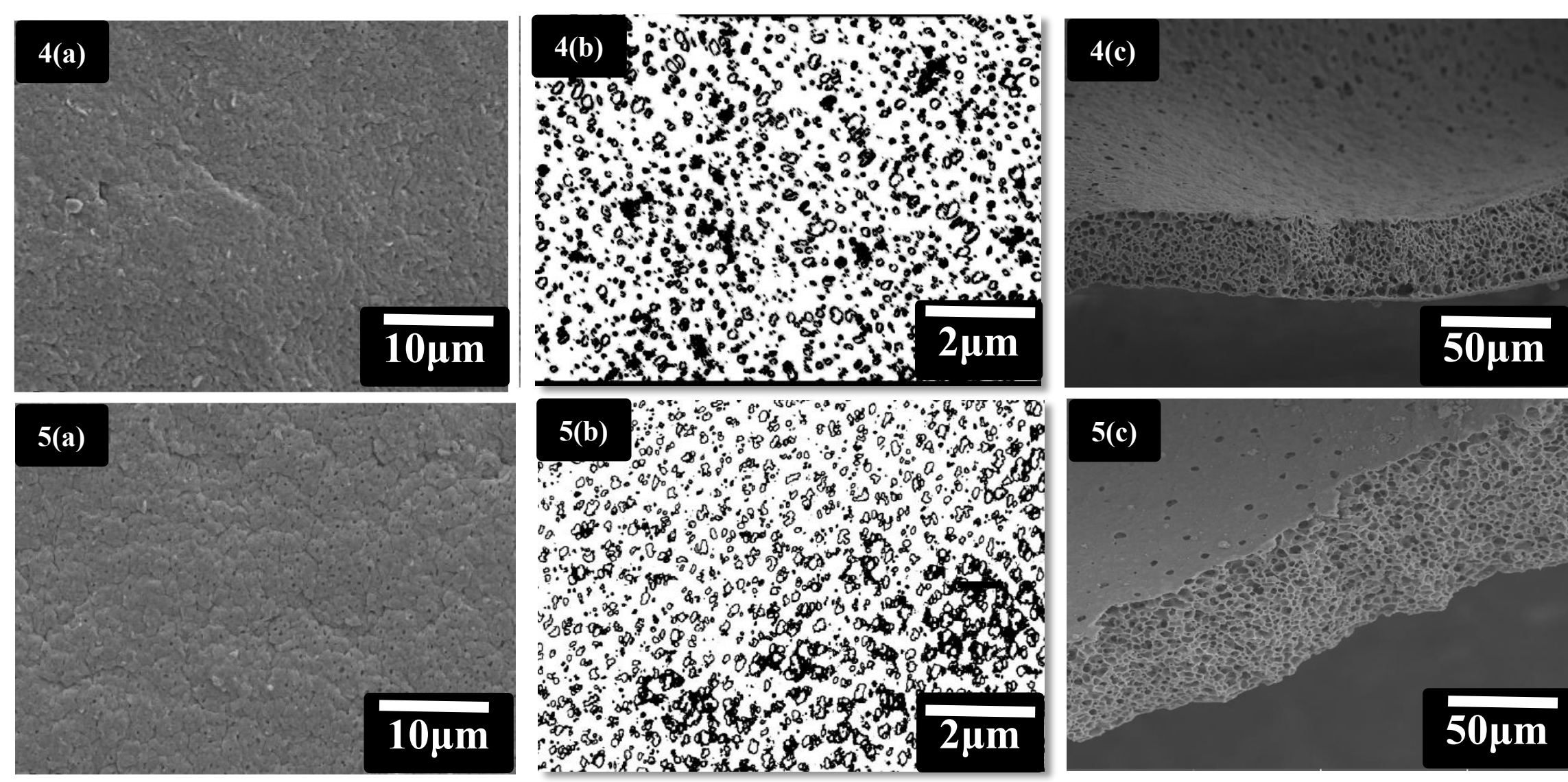

5(b)

5(b)

$5(c)$

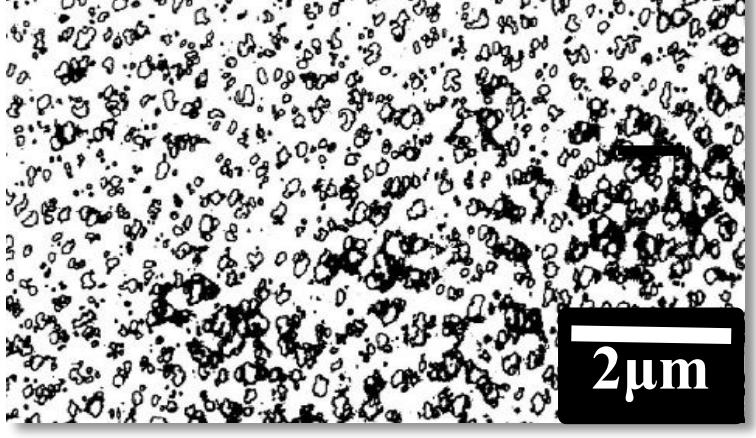
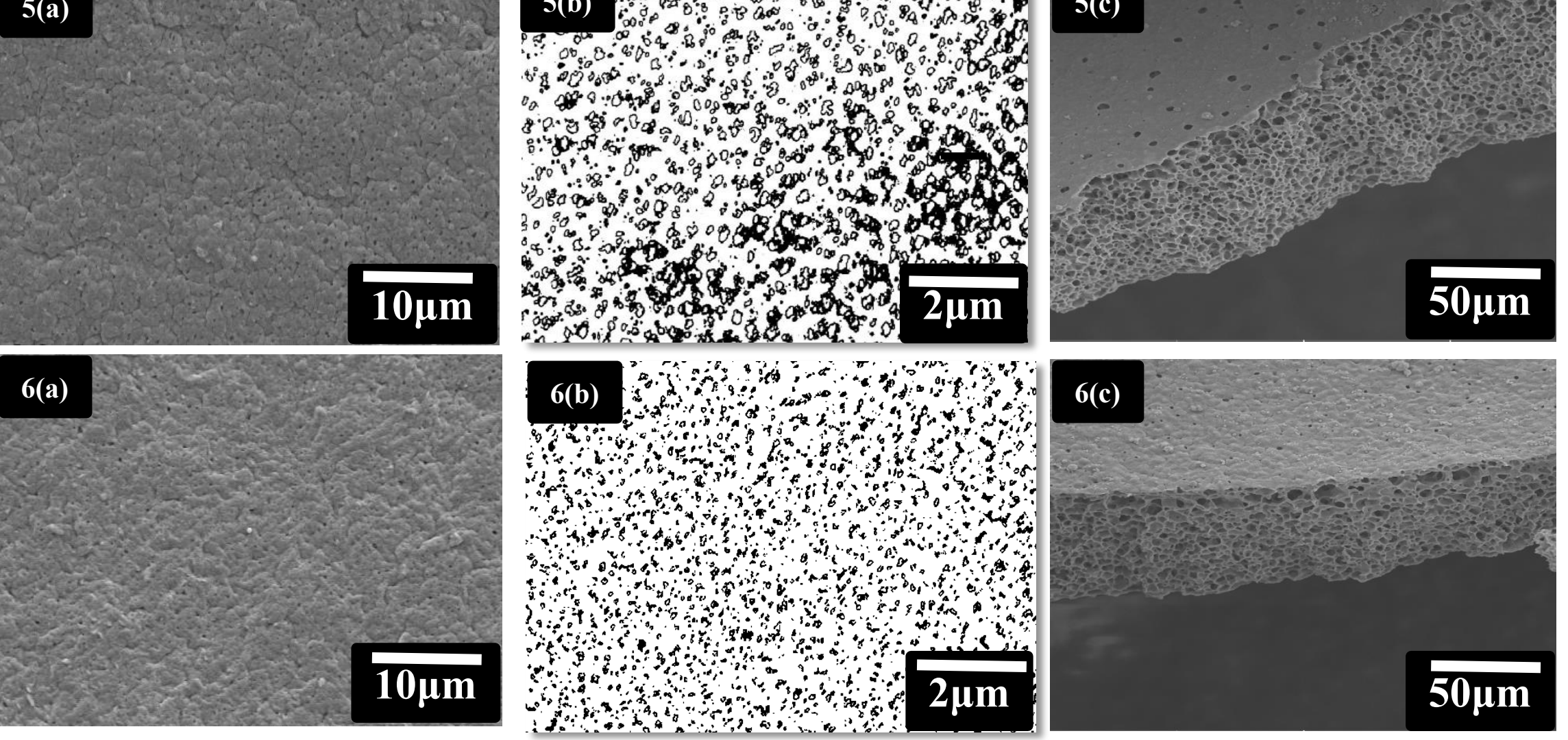

6(b)

6(c)
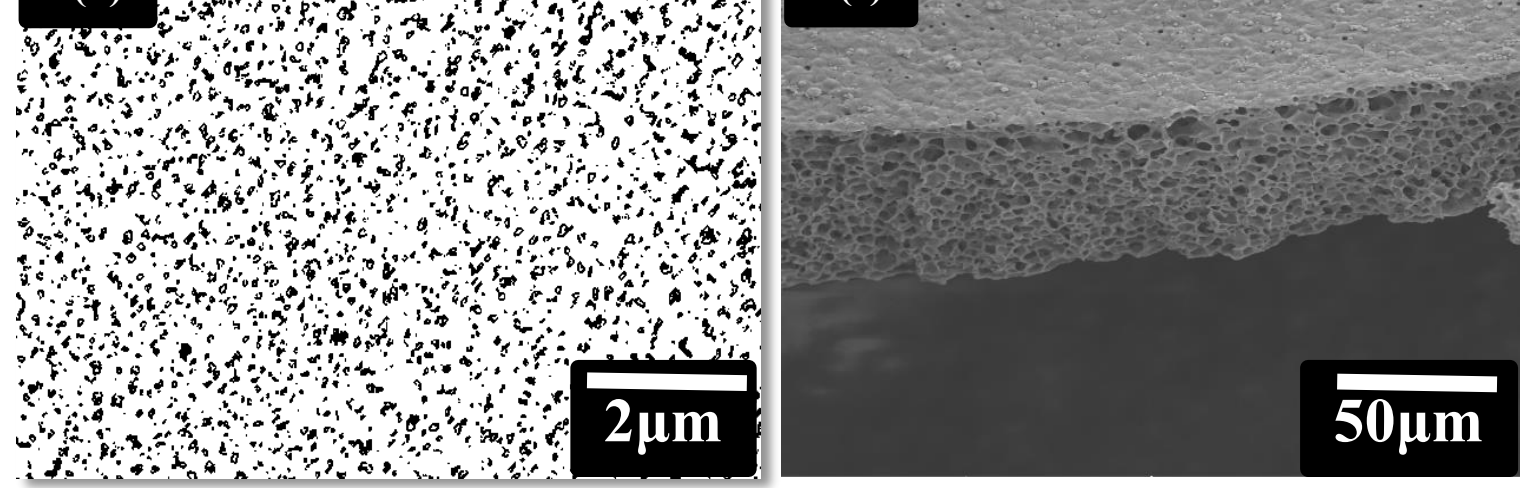
Fig. 3. 1(a) Surface morphology 1(b) Pore geometry analysis 1(c) Cross-sectional images of pure PVDF membrane. 2(a) Surface morphology 2(b) Pore geometry analysis 2(c) Cross-sectional images of PVDF/PANI membrane. 3(a) Surface morphology 3(b) Pore geometry analysis 3(c) Cross-sectional images of PG1 composite membrane. 4(a) Surface morphology 4(b) Pore geometry analysis 4(c) Cross-sectional images of PG2 composite membrane. 5(a) Surface morphology 5(b) Pore geometry analysis 5(c) Cross-sectional images of PG3 composite membrane. 6(a) Surface morphology 6(b) Pore geometry analysis 6(c) Cross-sectional images of PG4 composite membrane. 

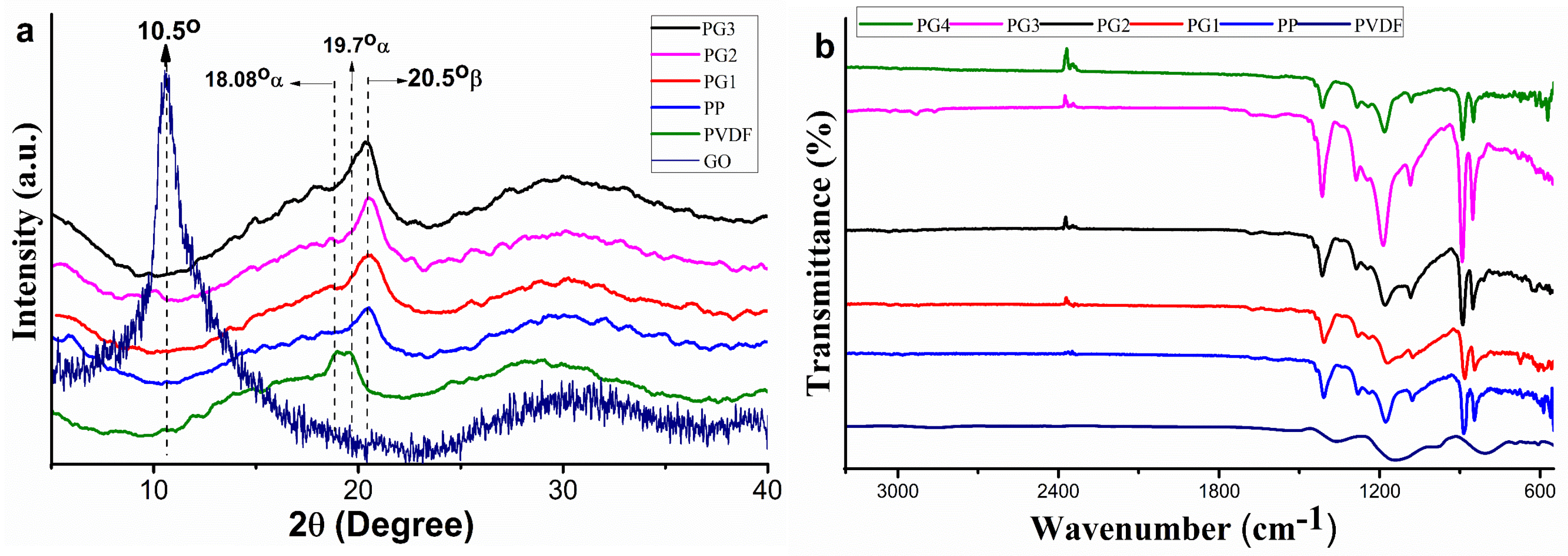

Fig. 4. (a) X-Ray diffractogram of GO, PVDF, PVDF/PANI and PVDF/PANI/GO composite membranes (b) FTIR spectra of PVDF, PVDF/PANI and PVDF/PANI/GO composite membranes. 

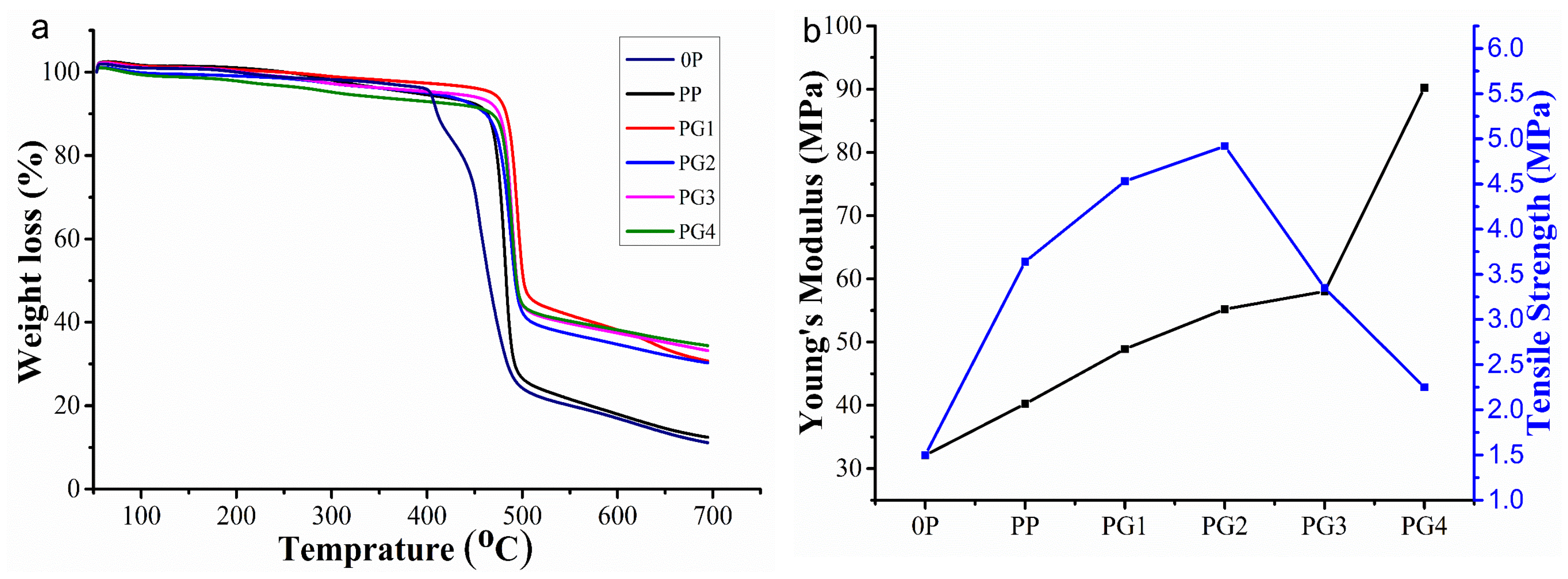

Fig. 5. (a) TGA and (b) tensile properties of pure PVDF, PVDF/PANI, and PVDF/PANI/GO composite membranes. 

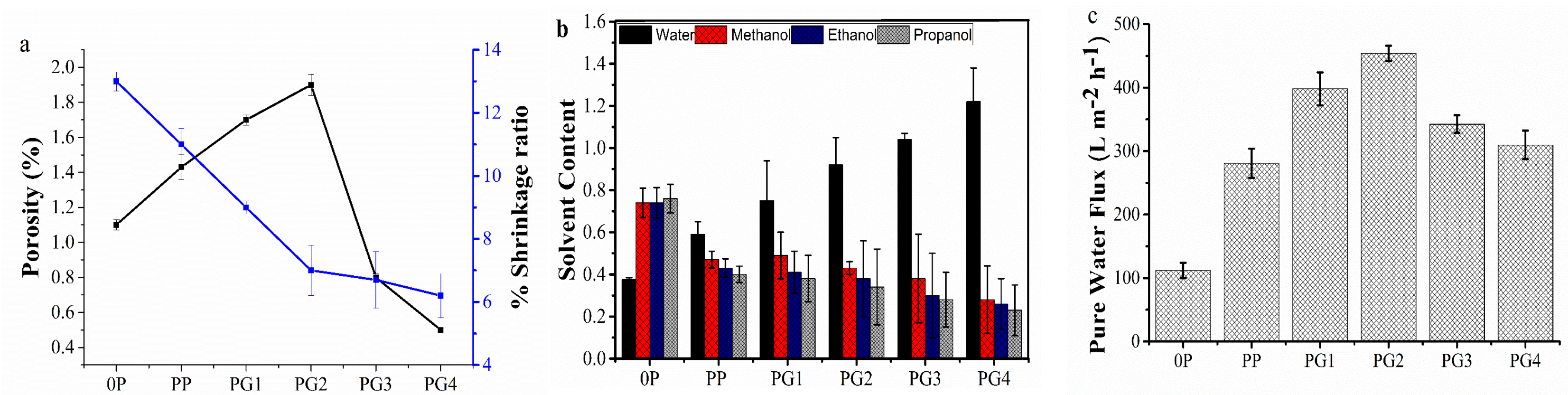

Fig. 6. Graphs for (a) Porosity and \% shrinkage ratio (b) Solvent content (c) Pure water flux of pure PVDF, $\mathrm{PVDF} / \mathrm{PANI}$, and PVDF/PANI/GO composite membranes. 
(a)

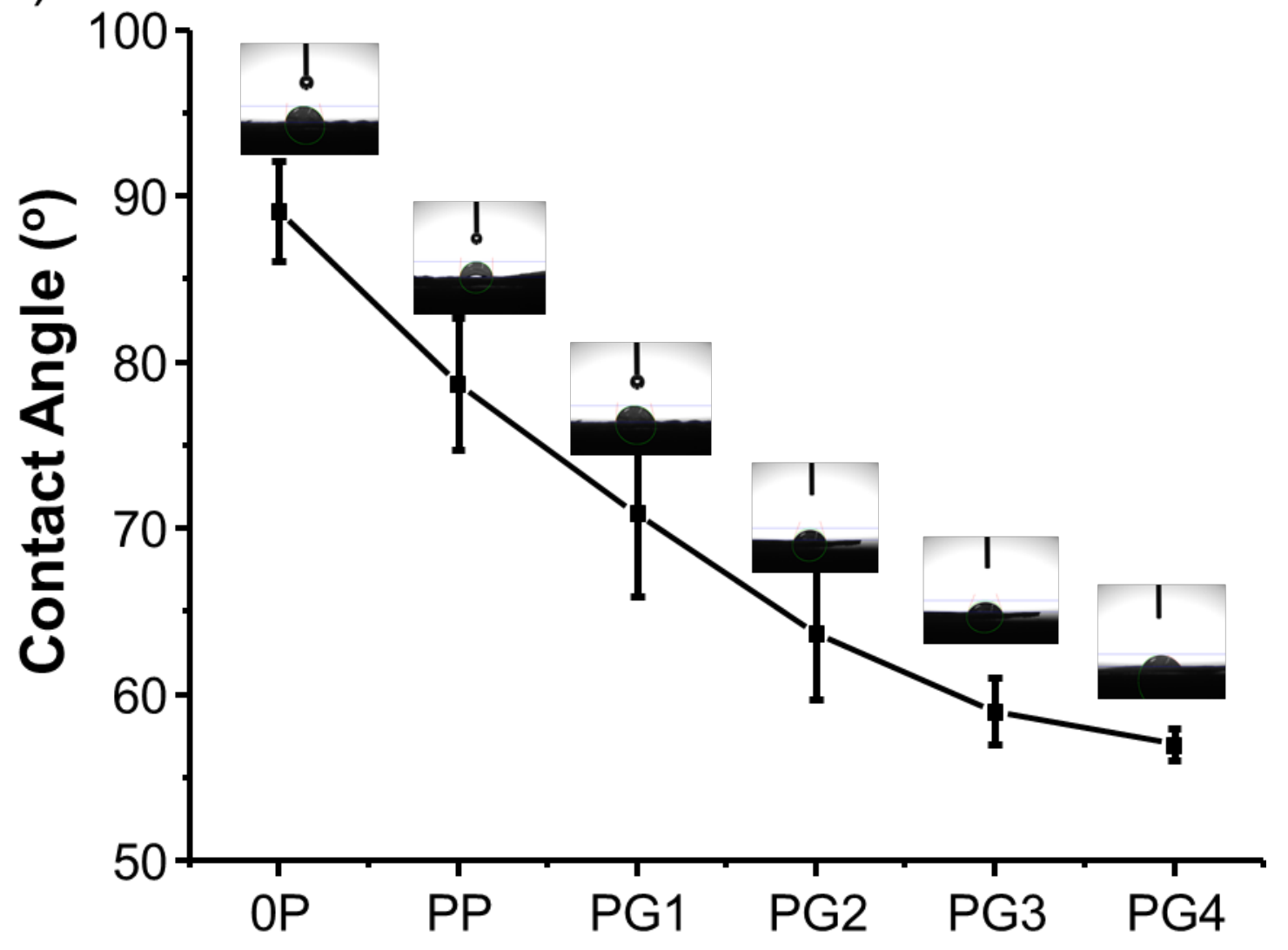

(b)

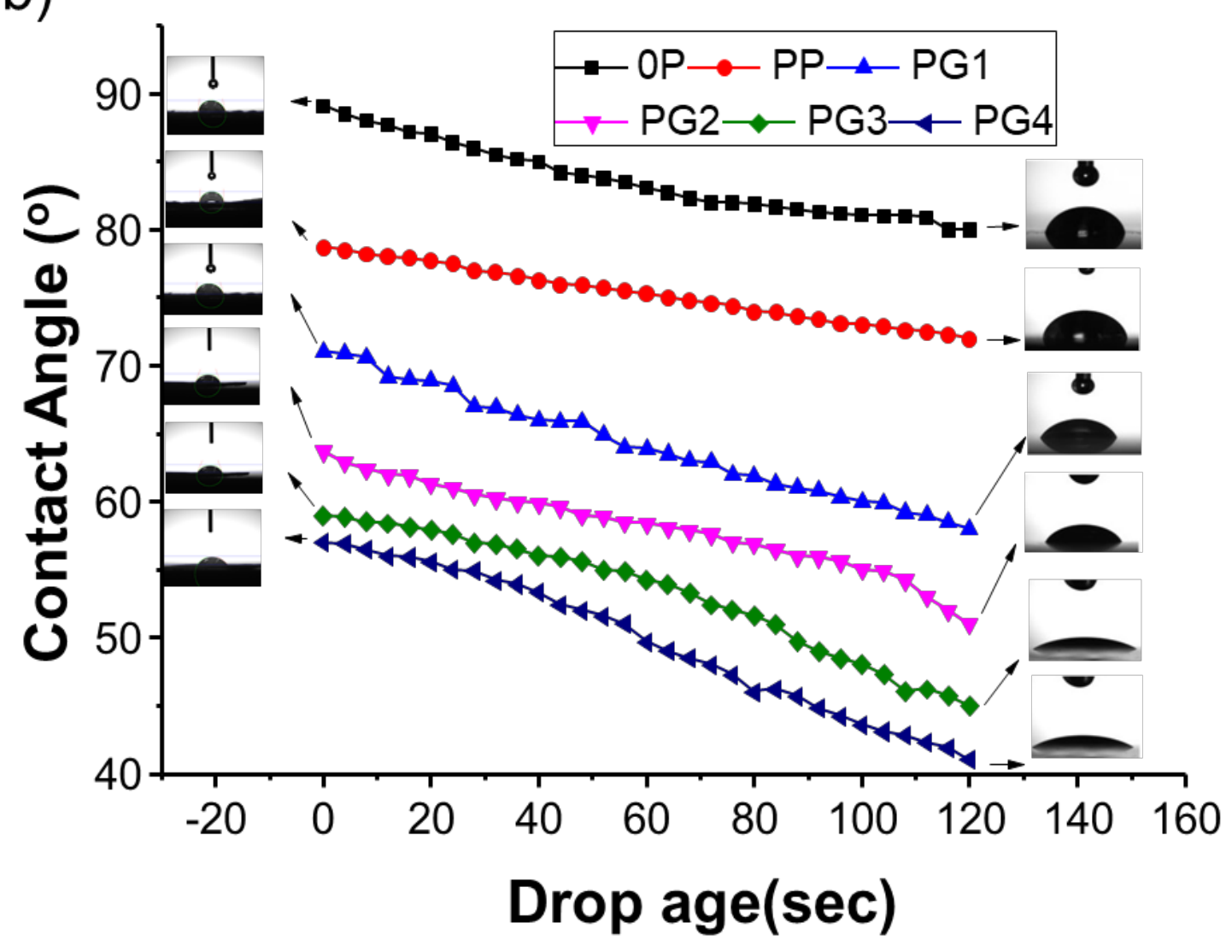

Fig. 7. (a) Contact angle (b) Time dependent contact angle of pure PVDF, PVDF/PANI, and PVDF/PANI/GO composite membranes. 

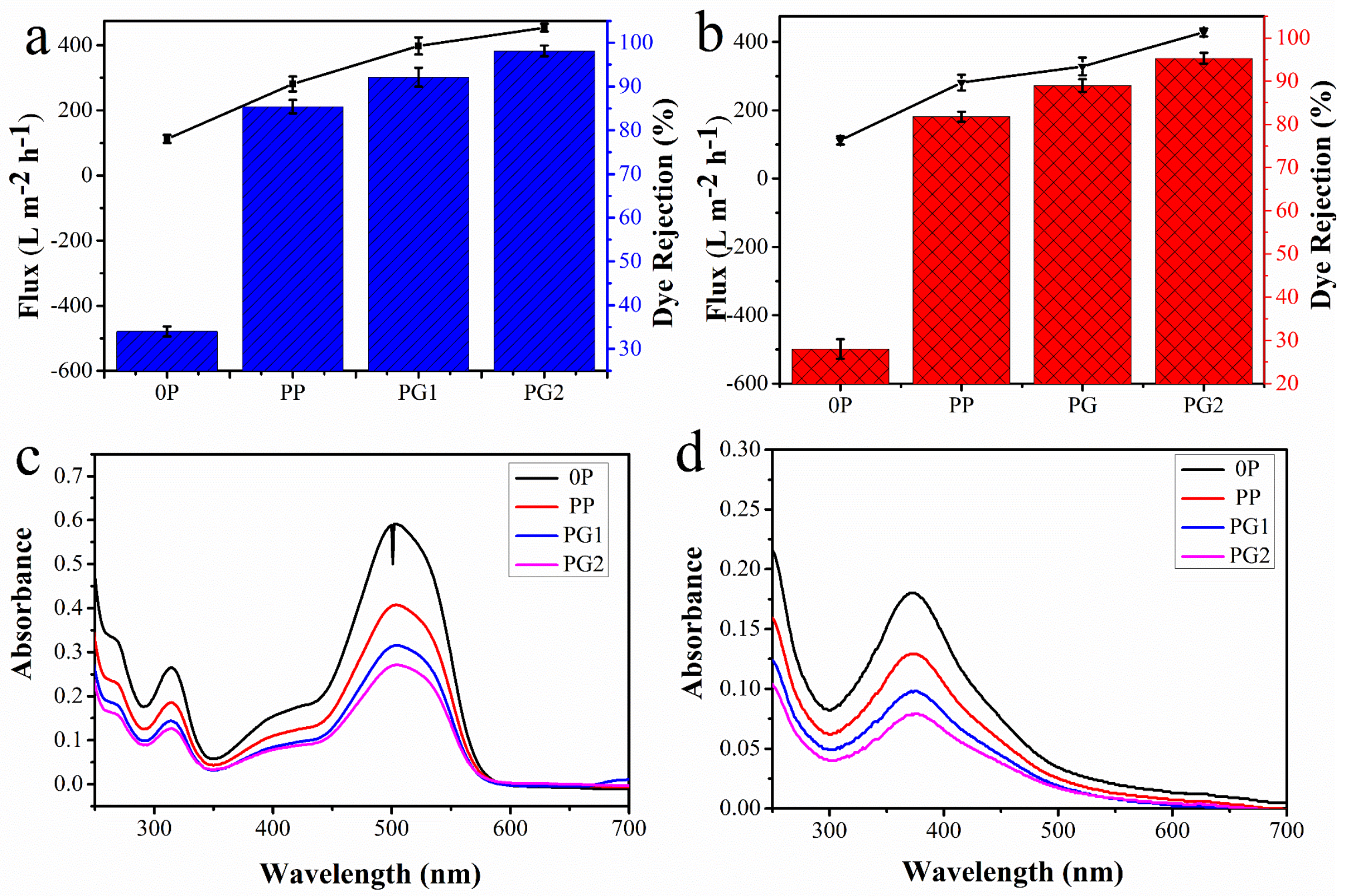

Fig. 8. Dye rejection and flux of (a) Allura Red and (b) Methyl Orange of pure PVDF, PVDF/PANI, and PVDF/PANI/GO composite membranes. UV-VIS Spectra of filtrate solution of (c) Allura Red and (d) Methyl Orange through pure PVDF, PVDF/PANI, and PVDF/PANI/GO composite membranes. 

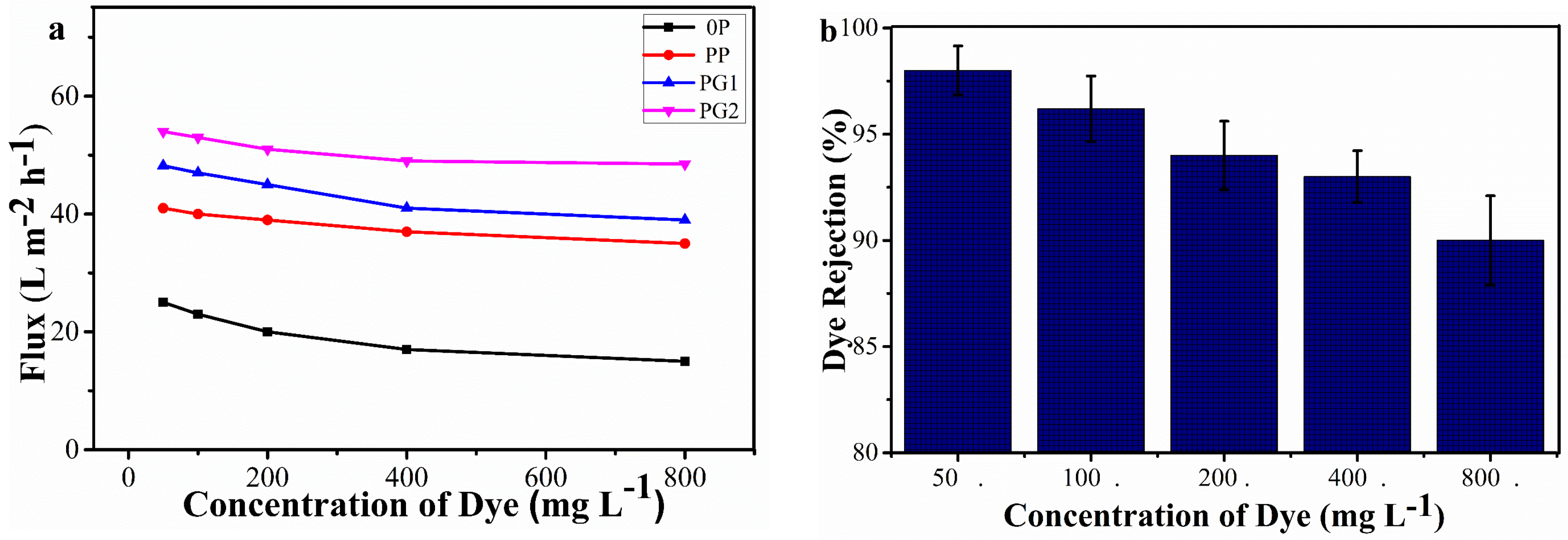

Fig. 9. Dye concentrations effect on (a) Dye flux of pure PVDF, PVDF/PANI, and PVDF/PANI/GO composite membranes (b) Dye rejection (\%) of PG2 composite membrane. 

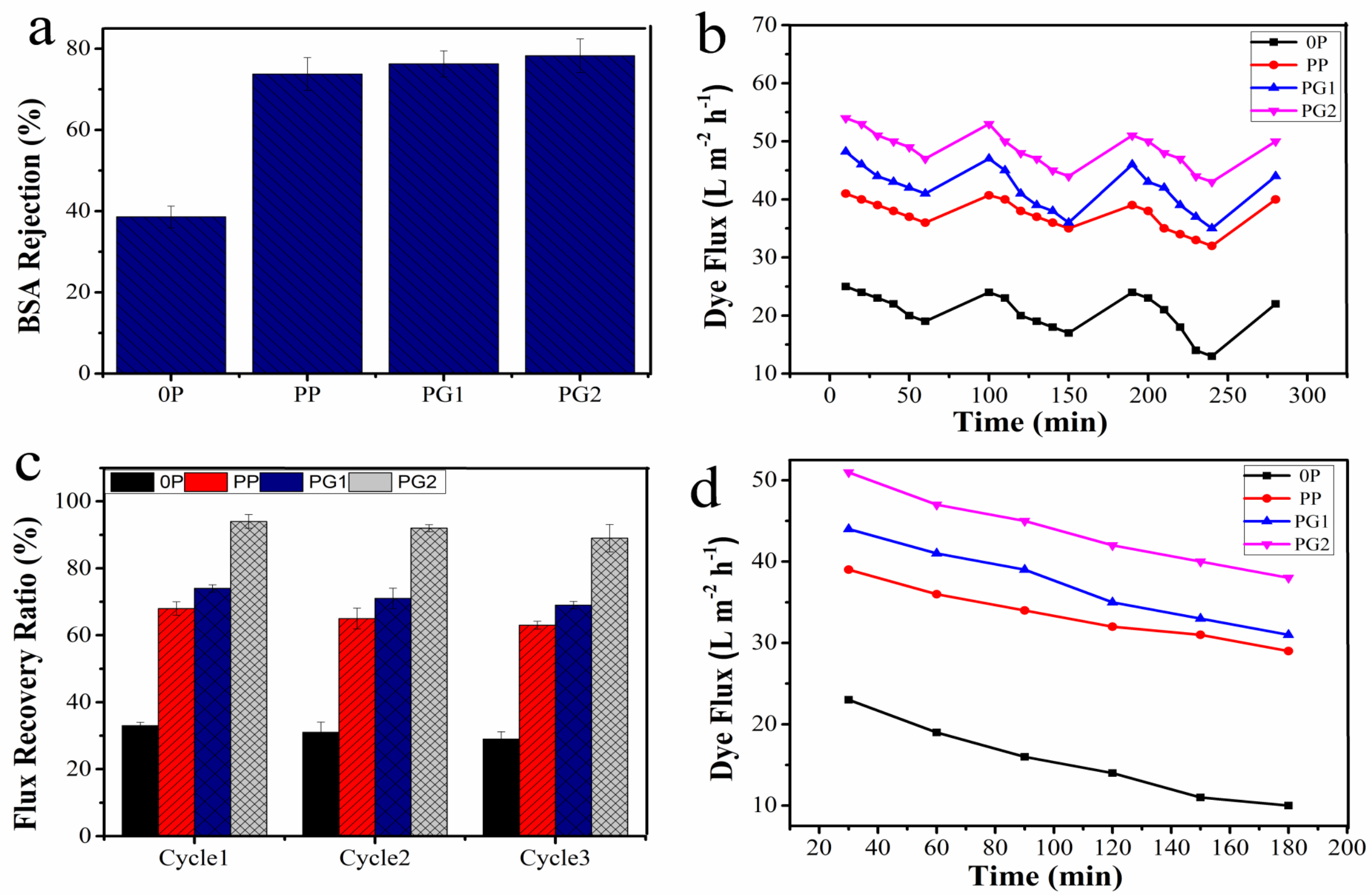

Fig. 10. (a) BSA rejection (b) Recycling properties (c) Flux recovery ratio in each cycle (d) Dye flux for long time of pure PVDF, PVDF/PANI, and PVDF/PANI/GO composite membranes. 


\section{Graphical Abstract}

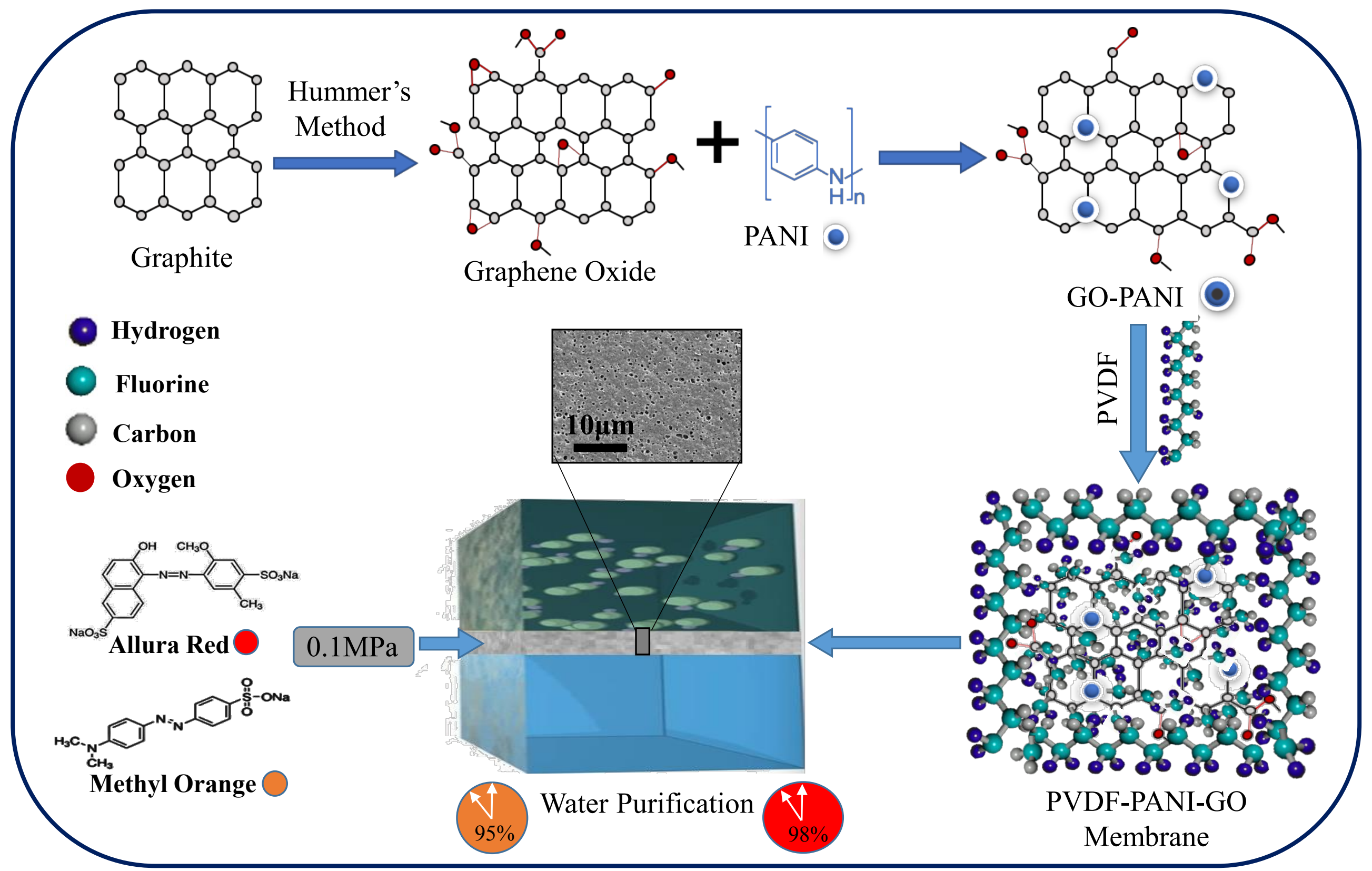

Graphite

Cydrogen

- Fluorine

Carbon

Oxygen

(n)

Methyl Orange $\bigcirc$
Water Purification
Membrane 